University of San Diego

Digital USD

2013-02-01

\title{
Elevated Blood Glucose Levels in the Emergency Department: Missed Opportunity for Informing and Referring
}

Melissa D. Rouse PhD, RN, CNS-BC, CEN, HACP, CPHQ

University of San Diego

Follow this and additional works at: https://digital.sandiego.edu/dissertations

Part of the Nursing Commons

\section{Digital USD Citation}

Rouse, Melissa D. PhD, RN, CNS-BC, CEN, HACP, CPHQ, "Elevated Blood Glucose Levels in the Emergency Department: Missed Opportunity for Informing and Referring" (2013). Dissertations. 442.

https://digital.sandiego.edu/dissertations/442

This Dissertation: Open Access is brought to you for free and open access by the Theses and Dissertations at Digital USD. It has been accepted for inclusion in Dissertations by an authorized administrator of Digital USD. For more information, please contact digital@sandiego.edu. 


\author{
UNIVERSITY OF SAN DIEGO \\ Hahn School of Nursing and Health Science \\ DOCTOR OF PHILOSOPHY IN NURSING
}

ELEVATED BLOOD GLUCOSE LEVELS IN THE EMERGENCY DEPARTMENT:

MISSED OPPORTUNITY FOR INFORMING AND REFERRING

by

Melissa D. Rouse, PhD(c), RN, CNS-BC, CEN, HACP, CPHQ

A dissertation presented to the

FACULTY OF THE HAHN SCHOOL OF NURSING AND HEALTH SCIENCE UNIVERSITY OF SAN DIEGO

In partial fulfillment of the requirements for the degree

DOCTOR OF PHILOSOPHY IN NURSING

February 2013

Dissertation Committee

Cynthia D. Connelly, PhD, RN, FAAN, Chair

Jane Georges, PhD, RN

Linda Urden, DNSc, RN, CNS, NE-BC, FAAN 


\begin{abstract}
The purpose of this research was to examine (1) the rates of elevated blood glucose $\geq 150$ $\mathrm{mg} / \mathrm{dL}$ in adults without a prior history of diabetes, receiving care for a non-diabetes related visit to the ED and (2) Emergency Department provider patterns for informing and referring discharged Emergency Department patients for follow-up of elevated random blood glucose levels. A descriptive, correlational, cross-sectional design, with purposive sample was used. Retrospective chart review was done for patients age 18 and older, treated in two EDs from March 1, 2010 through March 22, 2010. Significant relationships were found between blood glucose level and BMI, previous blood glucose level $\geq 150 \mathrm{mg} / \mathrm{dL}$, age, and reason for visit. Twenty five hundred and fifly five patients were seen over the 9-day study period. Fourteen hundred and forty patients had a random blood glucose level resulted by the lab. 106 patients had a blood glucose level $\geq 150$ $\mathrm{mg} / \mathrm{dL}$ without a history of diabetes. Forty-two and a half percent $(n=45)$ of the 106 patients were discharged, $50 \%(n=53)$ were admitted, and the rest $(n=8)$ were transferred to another hospital or a psychiatric unit for admission. Of those discharged $(n=45)$, only one patient $(2.2 \%)$ was informed about the elevated blood glucose level and referred for follow-up.
\end{abstract}




\section{Dedication}

This dissertation is dedicated to the special people in my life who allowed me time to work on this, gave me the words of encouragement to keep going and the support to keep it all together!

To my Holy Father in Heaven: Thank you for all the gifts you have given me as well as the opportunities to use them in so many ways, to give you Glory!

To my mother, Mary M. Alexander: Thank you for always believing in me and encouraging me. Thanks for the "You can do it!" and "Way to go girl!" responses to all my endeavors and accomplishments. Thanks for being my editor on this work.

To my husband, Michael J. Rouse: Thank you for being my best friend and my biggest fan! Thanks for picking up the pieces so that I could dedicate so much time to school and my career. You are my best friend and forever love!

To my amazing children, Nicholas, Michael, Amanda and Fmily: Thank you for giving me the space and encouragement to work an absurd amount of time on school assignments over the years.

To my USD PhD student colleagues: Thanks for the memories and fun as we went through the frustrations and triumphs of completing this program. You are all amazing and intelligent people. 
To my Palomar Health Family: Thanks for the support and encouragement. For those who did this before me and told me how life changing it would be and those who did this with me and shared in the adventure. I love you all! 


\section{Acknowledgements}

I would like to express my sincere appreciation and thanks to the amazing women that supported me during this endeavor.

To my dissertation committee:

Dr. Cynthia Connelly - My dissertation chair who read and revised my dissertation and publication so many times. Thank you for hanging in there with me as I learned this process!

Dr. Jane Georges - Thank you for getting me started and pushing me forward in dissertation seminar. 1 appreciated the never-ending words of encouragement throughout my $\mathrm{PhD}$ program!

Dr. Linda Urden - Thank you for being there through both of my graduate degrees. You have been a great mentor. Having you on my committee was meant to be! I would also like to acknowledge a few others who were instrumental in helping me through the PhD experience.

Dr. Ann Mayo - Thank you for your positive attitude and nonthreatening way of presenting quantitative and qualitative methods. You are an inspiration!

Dr. Mary Jo Clark - Thank you for teaching me so much about writing in my Writing for Publication class. 
Cristina Shoukry - Thanks for being my research partner, for identifying this important health issue, and helping to collect the initial data set. Thanks for being my cheerleader!

Susie Merrill- Thanks for having answers to my many questions. Thanks for your helpful demeanor, smile and positive attitude.

Cathy Mumper - Thanks for making the NFLP process smooth and seamless. 
TABLE OF CONTENTS

CHAPTER I: STATEMENT OF THE PROBLEM ………………............... 1

Background and Significance ……………………………....................... 1

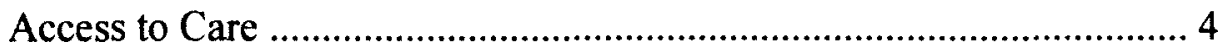

Conceptual Framework ………....................................................... 6

Research Questions .......................................................................... 8

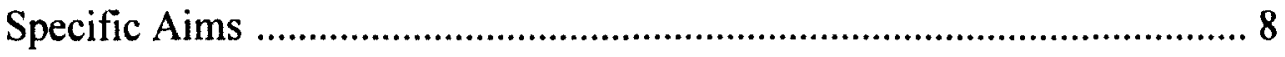

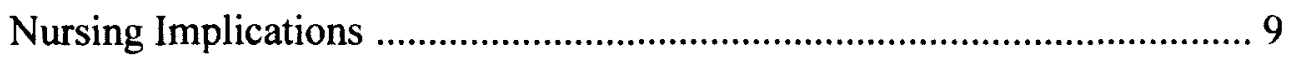

CHAPTER II: REVIEW OF THE LITERATURE ………........................... 12

Conceptual Framework ....................................................................... 12

Principal Literature Review .................................................................... 13

Elevated Blood Glucose Levels ......................................................... 13

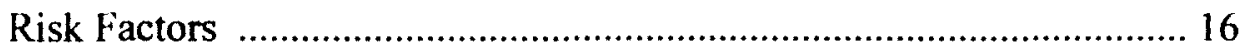

Body Mass Index (BMI) ……………….................................. 17

Blood Pressure ………....................................................... 18

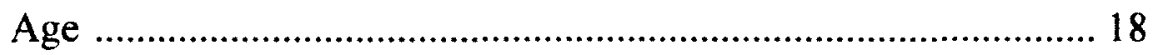

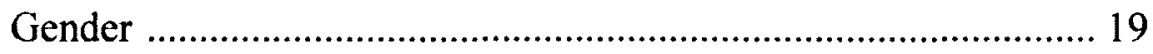

Race/Ethnicity ....................................................................... 19

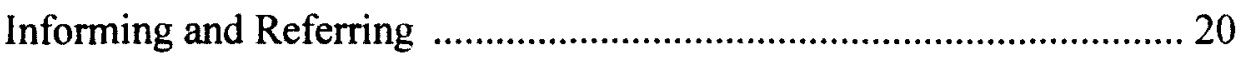

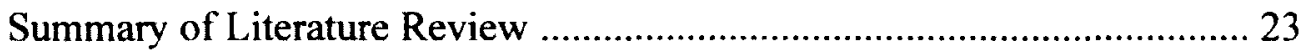




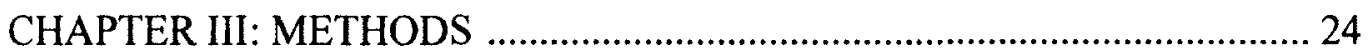

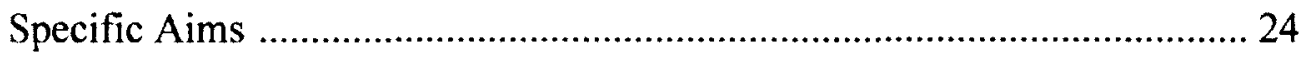

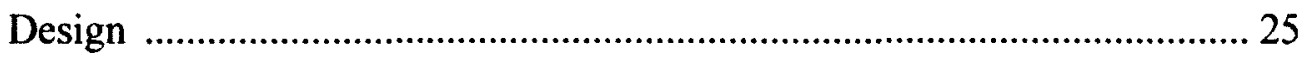

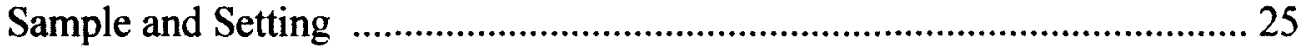

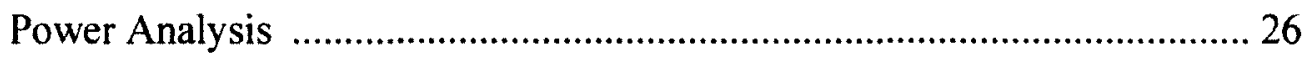

Variables and Operational Definitions ……………..................................... 26

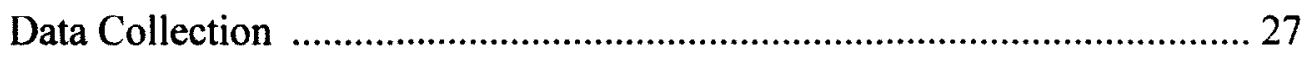

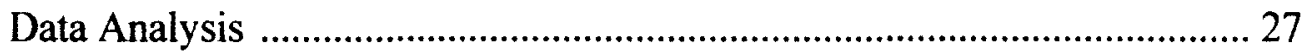

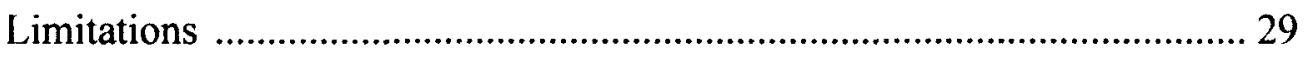

Protection of Human Subjects ………..................................................... 29

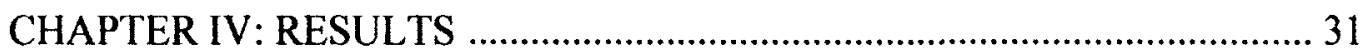

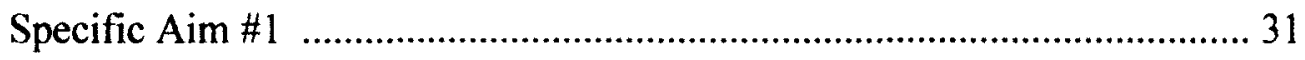

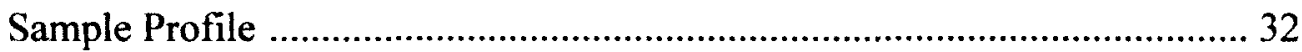

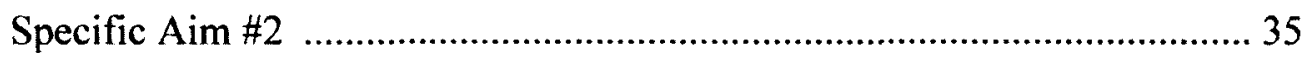

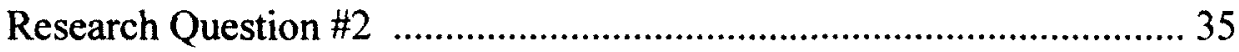

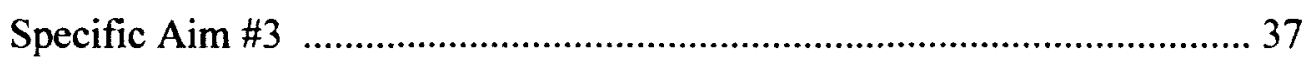

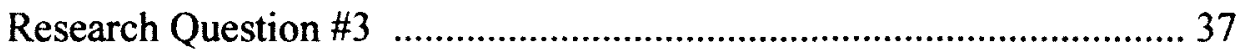

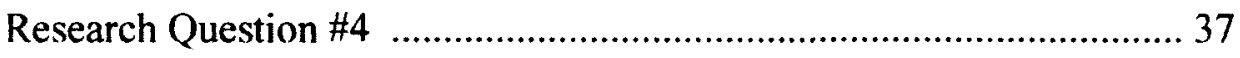

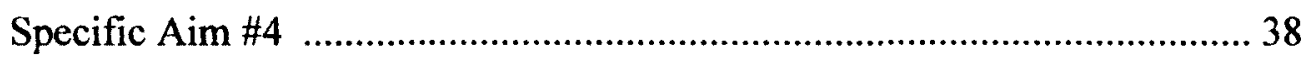

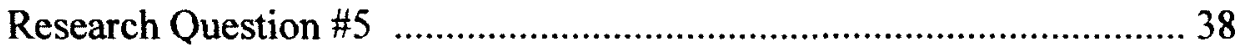


CHAPTER V: DISCUSSION OF FINDINGS ............................................... 39

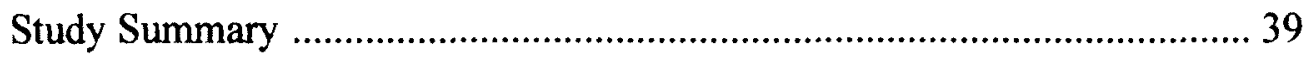

Importance to Advancement of Knowledge ................................................. 45

Conclusion and Implications for Nursing ................................................ 45

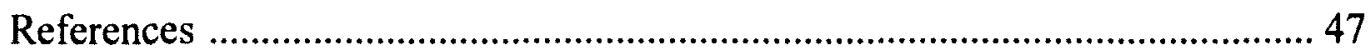

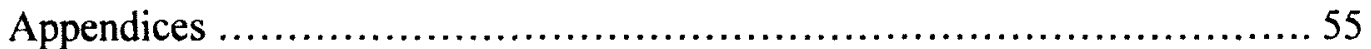




\section{LIST OF TABLES}

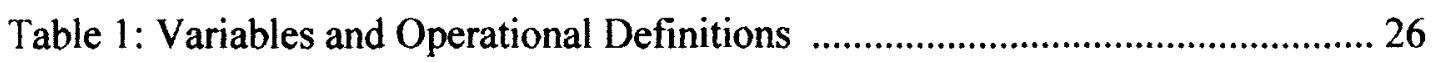

Table 2: Sample Characteristics .......................................................................... 33

Table 3: Health-Related Parameters .................................................................... 34

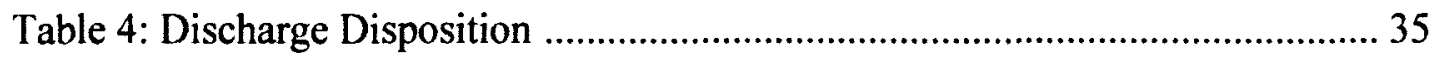

Table 5: Correlations between Independent Variables and Blood Glucose Levels . 36 


\section{LIST OF ILLUSTRATIONS}

Figure 1. The Revised Health Promotion Model (Pender, 1996) 


\section{CHAPTER I \\ STATEMENT OF THE PROBLEM}

Prediabetes is prevalent, continues to increase, and costs the United States over $\$ 25$ billion annually (Zhang et al., 2009). A patient may have prediabetes and its adverse micro- and macro-vascular complications for up to seven years before diabetes is diagnosed (Aroda \& Ratner, 2008; Harris, Klein, Welton, \& Knulman, 1992). Early identification and treatment of patients who may have undiagnosed prediabetes is essential in preventing or delaying progression to type 2 diabetes (Bergman, 2010; Hsueh, Orloski, \& Wyne, 2010). In 2011, 79 million Americans had prediabetes, and seven million were undiagnosed (American Diabetes Association [ADA], 2011b). Incidence is expected to increase to 472 million people worldwide by 2025 (Shehab Eldin, Emara, \& Soker, 2008). Mitigating this global public health issue requires identifying those with undiagnosed prediabetes and initiating measures to stop or delay progression to type 2 diabetes (Bergman, 2011).

\section{Background and Significance}

The National Diabetes Data Group (1979) originated the concept of impaired glucose tolerance (IGT), a condition exemplified by an elevated blood glucose level that 
was not diabetes but increased a person's risk for diabetes (Abdul-Ghani \& DeFronzo, 2009). In 1997, the Expert Committee on the Diagnosis and Classification of Diabetes Mellitus further elaborated this phenomenon to include another category called impaired fasting glucose (IFG). They argued an elevated IGT or IFG, or both, indicated increased risk for type 2 diabetes mellitus and constituted prediabetes (Abdul-Ghani \& DeFronzo, 2009; Buysschaert \& Bergman, 2011).

Prediabetes mellitus, a term coined over a decade ago by the U.S. Department of Health and Human Services and the ADA (Shehab Eldin, Emara, \& Shoker, 2008), is defined as a state in which cells no longer respond appropriately to insulin, a hormone that regulates blood sugar (Vagnini, 2010). Prediabetes is considered a diagnosis, but it is also considered a risk state that warrants consideration of lifestyle changes and medication to reduce the risk of progression to type 2 diabetes (Shaw, 2011).

Normal blood glucose levels increase after eating a meal but should not exceed 135-140 mg/dL (Charfen, Ipp, Kaji, Saleh, Qazi, \& Lewis, 2009). A review of the literature finds a lack of consensus in what constitutes a blood level indicative of elevated blood glucose. For example, a random non-fasting blood sugar level in a person without diabetes should be in the low to mid-100's mg/dL (Virginia Mason Team Medicine, 2013).

Other sources argue a random blood sugar in a healthy person without diabetes, should be less than $125 \mathrm{mg} / \mathrm{dL}$ (WebMD, 2011). In contrast, Ginde, Savaser, and Camargo (2009) defined anything less than $140 \mathrm{mg} / \mathrm{dL}$ to be a normal glucose level. The ADA defines hyperglycemia in the hospital setting, which includes the emergency department (ED), as a blood glucose $>140 \mathrm{mg} / \mathrm{dL}$ (ADA, 2012). Although a recent meal, 
stress, medications, infections, and pain may result in an elevated blood glucose level (Davidson \& Moreland, 2009), the elevated level may also be an indicator of prediabetes, which warrants further testing (Ginde, Delaney, Pallin, \& Camargo, 2010).

Prediabetes risk or diagnosis is determined by performing specific tests such as a fasting blood glucose test. The result is impaired fasting glucose (IFG). Prediabetes is defined as elevated blood glucose levels with IFG between 100 and $125 \mathrm{mg} / \mathrm{dL}$ (AbdulGhani \& DeFronzo, 2009). However, others argue an IFG level with anything greater than $90 \mathrm{mg} / \mathrm{dL}$ puts a patient at risk and should be considered the level for prediabetes (Nichols, Hiller, \& Brown, 2008; Shaw, Zimmet, \& Hodge, 2000). IGT levels between 140 and $200 \mathrm{mg} / \mathrm{dL}$ or elevated IFG and IGT are considered to be indicative of prediabetes (Biuso, Butterworth, \& Linden, 2007; Fonseca, 2007; Zhang et al., 2009). In prediabetes, the serum blood glucose levels are elevated but are not high enough to be diagnosed as type 2 diabetes (Canadian Diabetes Association, 2012; Fonseca, 2007), nonetheless if left untreated, people with elevated blood glucose levels are predisposed to develop type 2 diabetes (Biuso, Butterworth, \& Linden, 2007; Fillman, 2010; Fonseca, 2007; Gossaine \& Aldosouqi, 2010; Shehab Eldin, Emara, \& Soker, 2008).

In 2010, the ADA recommended another important lab test for identifying prediabetes, the glycolated hemoglobin Alc (Also known as: $\mathrm{Alc}, \mathrm{HgAlc}$ or $\mathrm{HbAlc}$ ). This blood test provides a snapshot of what the blood glucose concentration has been over a period of time (Dugger \& Clark, 2011), specifically the average plasma glucose from the prior 90 days. An AlC of $5.7 \%$ to $6.4 \%$ is considered to be indicative of prediabetes (ADA, 2010; Buysschaert \& Bergman, 2011; Dugger \& Clark, 2011; Silverman et al., 2011). 


\section{Access to Care}

For many, the Emergency Department (ED) is the only source of medical care or interaction with a health care provider. This makes the ED an ideal place to identify those with elevated random blood glucose levels and refer them for more specific testing for prediabetes and diabetes (Charfen et al., 2009; Ginde et al., 2010; Silverman et al., 2006). Because ED patients may have had oral intake before arriving in the ED, the serum blood glucose level is considered random (unknown last oral intake; Fonseca, 2007).

In 2004, the ADA recommended early detection of prediabetes (Charfen et al., 2009). This suggests screening of the general population for prediabetes would be beneficial. Norris, Kansagara, Bougatsos, and Fu (2008) published a review of the evidence debating the benefits or harm of screening and found a lack of evidence to support universal screening. In 2011, the ADA revisited the issue and recommended standardized protocols for screening. Unfortunately, screening for prediabetes is not routinely done.

Health care professionals regularly care for patients experiencing the phenomenon of elevated blood glucose in a variety of settings, including hospitals, emergency departments, doctor's offices, and clinics. In 2008, the American Association of Clinical Endocrinologists urged physicians to identify prediabetes and begin treatment, such as lifestyle changes, including diet, exercise, and possible medication use. Lifestyle modification has been shown to prevent or delay the risk of progression from prediabetes to type 2 diabetes by up to $58 \%$ (Diabetes Prevention Program Research Group, 2002; Tuomilehto et al., 2001). With the incidence of diabetes increasing each year, a chance to 
identify patients with possible prediabetes who could make lifestyle changes to prevent progression to type 2 diabetes is an important health promotion opportunity that should not be missed.

Several landmark studies have shown the efficacy of lifestyle modifications such as diet, exercise, and even the addition of medication to prevent advancement from prediabetes to diabetes (Diabetes Prevention Program Research Group, 2002; Lindstrom et al., 2003; Pan et al., 1997). The health care system is burdened with patients who present with multiple comorbidities. Prevention of health care complications is necessary, but impossible unless patients are educated about their risk and informed if they have abnormal laboratory results. The Affordable Care Act addresses the need for prevention, including the need to identify and prevent diseases (Koh \& Sebelius, 2010).

Early identification will give patients the opportunity to make lifestyle choices to prevent or delay progression to type 2 diabetes, thus preventing negative impact on the individual, society, health care system, and health care costs (Biuso et al., 2007; Cali \& Caprio, 2008; Fonseca, 2007; Hoerger et al., 2007; James et al., 2011). Lifestyle modification has been shown to prevent or delay the risk of those with prediabetes from progressing to type 2 diabetes by up to 58\% (Diabetes Prevention Program Research Group, 2002; Tuomilehto et al., 2001).

Notably, the ED may be an opportune location for identifying patients with prediabetes (Ginde, Delaney, Lieberman, Vanderwell, \& Camargo, 2007), which is key in gaining control of this growing epidemic (Colagiuri, 2011). Although previous studies have reported conflicting findings regarding the percentage of patients presenting to the Emergency Department with blood glucose levels suggesting prediabetes, the ED is 
recognized as an ideal place to identify, inform, and refer patients for follow-up (Ginde et al., 2007).

The purpose of this study was to examine (1) the rates of elevated blood glucose levels $\geq 150 \mathrm{mg} / \mathrm{dL}$ in adults without a history of diabetes, receiving care for a nondiabetes related emergency room visit and (2) Emergency Department provider patterns of informing and referring discharged patients without a history of Diabetes Mellitus (DM) for follow-up of elevated random blood glucose levels.

\section{Conceptual Framework}

To study the importance of recognizing and responding to elevated blood glucose levels in the emergency department, Pender's Health Promotion Model is the conceptual framework guiding this study (Figure 1). Nola J. Pender, a health promotion advocate, created the health promotion model in 1982 and revised it in 1996 (Nursing Planet, 2012). According to Pender, health promotion and disease prevention should be the primary focus in health care. Health promotion, an approach to wellness, is defined as behavior motivated by the desire to increase well-being and actualize human health potential. This model was created to show the relationships between individual characteristics and experiences, behavior specific conditions and affects, and behavioral outcomes. Pender advocated addressing health issues and behaviors in an effort to promote health and prevent disease (Nursing Planet, 2012). 


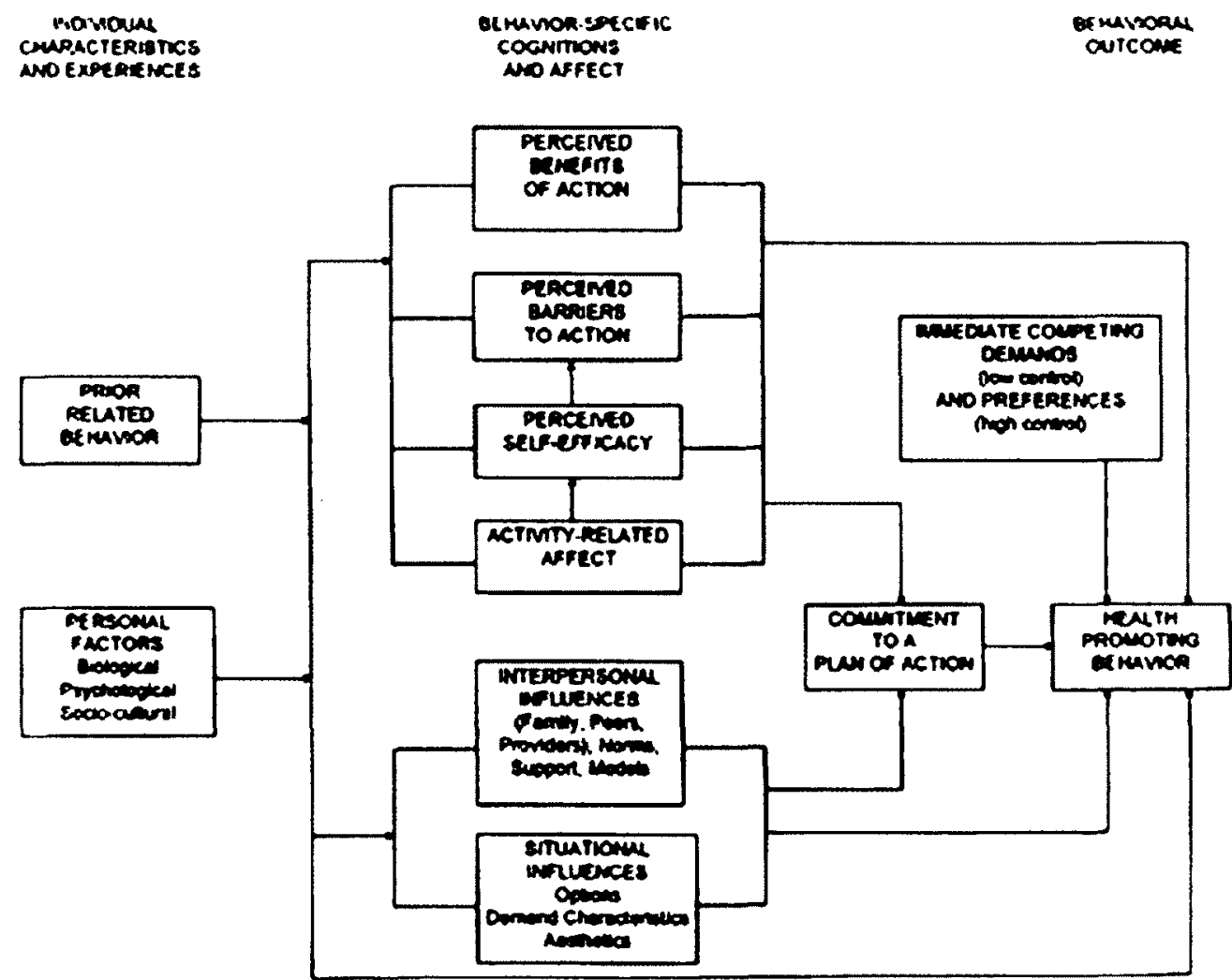

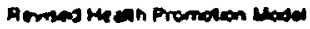

Figure 1. The revised health promotion model (Pender, 1996).

Identification of an elevated blood glucose level ( $\geq 150 \mathrm{mg} / \mathrm{dL})$, during a non-diabetes related visit to the ED fits into Pender's Conceptual Model. The middle column labeled "Behavior-Specific Conditions and Affect" shows an opportunity for an interpersonal influence. An example occurs when a provider informs a patient about an elevated blood glucose value and refers him or her for follow-up testing. When the patient follows up with another provider, he or she is making a "commitment to a plan of action" as listed on the model. If follow-up testing shows the patient has prediabetes, he or she will be able to make lifestyle changes and start a treatment regimen to change the course of the disease process. 


\section{Research Questions}

The research questions to be answered in this study are

1. What are the characteristics of a group of adults (random blood glucose, Body Mass Index [BMI], blood pressure [BP]), and select demographic characteristics (age, gender, race/ethnicity) receiving care for a non-diabetes related visit to the ED?

2. What are the relationships between and among the dependent variable of blood glucose level and independent variables (BMI, elevated BP $[\geq 130 / 80]$, history of hypertension, previous blood glucose $\geq 150 \mathrm{mg} / \mathrm{dL}$ and selected demographic characteristics) in a group of adults receiving care for a nondiabetes related visit to the ED?

3. What are the rates of elevated blood glucose $\geq 150 \mathrm{mg} / \mathrm{dL}$ in adults without a history of diabetes receiving care for a non-diabetes related emergency room visit?

4. What are emergency department provider patterns of informing and referring discharged emergency department patients without a history of diabetes for follow-up of elevated random blood glucose in a group of adults receiving care for a non-diabetes related visit to the ED?

\section{Specific Aims}

1. To characterize a group of adults (random blood glucose, Body Mass Index [BMI], blood pressure [BP]), and select demographic characteristics (age, gender, race/ethnicity) receiving care for a non-diabetes related visit to the ED. 
2. To describe the relationships between and among the dependent variable of blood glucose level and independent variables (BMI, elevated BP $[\geq 130 / 80]$, history of hypertension, previous blood glucose $\geq 150 \mathrm{mg} / \mathrm{dL}$, and selected demographic characteristics) in a group of adults receiving care for a nondiabetes related visit to the ED.

3. To examine the rates of elevated blood glucose $\geq 150 \mathrm{mg} / \mathrm{dL}$ in adults without a history of diabetes receiving care for a non-diabetes related emergency room visit.

4. To examine emergency department provider patterns of informing and referring discharged emergency department patients without a history of diabetes for follow-up of elevated random blood glucose in a group of adults receiving care for a non-diabetes related visit to the $\mathrm{ED}$.

\section{Nursing Implications}

Nurse scientists are focusing on research to improve patient health and outcomes. Pender's Health Promotion Model theorizes health care providers, which for the purpose of this study include nurses, physicians, and physician assistants, have interpersonal influence through their communication with patients. Communication about lab tests and findings can help influence and encourage patients to take an active role in improving health and well being.

It is highly probable the ED visit may be the only opportunity for some patients to interface with a health care provider. This makes the ED an ideal place to identify elevated blood glucose levels, refer patients for follow-up of the elevated blood glucose level, and stress the importance of follow-up. ED nurses and providers play a key role in 
affecting the opportunity for patients to make important choices about health and wellbeing. With proper referral and follow-up to diagnose prediabetes, the patient will be able to make important decisions and changes in lifestyle to prevent further progression of this risk state.

The results of this study will inform nurses and providers about this patient population who may have undiagnosed prediabetes or type 2 diabetes. It will increase their awareness of the current missed opportunities for educating patients to allow them to make choices to delay or prevent progression to type 2 diabetes. The results will increase ED provider awareness of the rate of patients with a blood glucose level greater than or equal to $150 \mathrm{mg} / \mathrm{dL}$ and encourage them to refer patients for follow-up. Followup for discharged patients could entail further assessment of lab values such as a fasting blood glucose, a glucose tolerance test, or an A1C.

The health care system is already burdened with the number of patients with multiple comorbidities. Prevention of health care complications is critical but impossible unless patients are informed of their risk. The Affordable Care Act addressed the need for prevention, which includes the need to identify and prevent diseases (Koh \& Sebelius, 2010). While screening patients for diabetes is not recommended (Norris et al., 2008), it is recommended that patients with an elevated blood glucose level be informed and referred (Bergman, 2010; Hsueh et al., 2010).

With the growing numbers of prediabetics each year, EDs need to adopt protocols to inform and refer patients with elevated blood glucose levels. Nurses must partner with ED providers (physicians and physician assistants) to educate patients about the risks and complications of prediabetes and the opportunity to make changes to prevent or delay 
progression to type 2 diabetes. ED nurses and providers play an integral role in affecting the ability for patients to make important choices about their health and well-being. 


\section{CHAPTER II}

\section{REVIEW OF THE LITERATURE}

The purpose of this chapter is to provide a summary of the literature about elevated blood glucose levels and prediabetes. It will include methods for testing (fasting glucose test, glucose tolerance test, and Alc) for this risk state that predisposes patients eventually to progress to type 2 diabetes. Risk factors for elevated blood glucose levels such as body mass index (BMI), elevated blood pressure, age, gender, and race/ethnicity will also be presented. Studies will be presented that support the importance of identifying patients with elevated blood glucose levels and informing and referring them for follow up testing in an effort to identify the risk state of prediabetes. Although there is support for testing, it is unclear what blood glucose level should be used as the cutoff point for referring patients. Gaps in the literature are identified to establish the need for this study.

\section{Conceptual Framework}

Pender's Health Promotion Model (Figure 1) was the conceptual framework guiding this study. This framework was chosen because the premise is patients will respond to the interpersonal influences of an ED provider informing and educating them 
about an elevated random blood glucose level. When the provider explains the risk: involved, refers the patient for follow up, and urges the patient to follow up for further testing, this will lead to the patient to making a commitment to action. The patient will follow up for further testing and then if they do, in fact, fit the criteria for the prediabetes risk state, the patient can make important decisions about lifestyle modifications to improve his or her health and well-being.

In a study conducted by Ginde et al. (2007), patients were supportive of the idea of screening for diabetes. Two-thirds $(n=604)$ of their patients were willing to have their blood drawn and tested to screen for diabetes. Ninety five percent said they would follow up if their value was abnormal and wanted to be informed. Nearly all stated they wanted to be referred for outpatient follow-up. This work provides support for the use of this framework for the study conducted here.

\section{Principal Literature Review}

A comprehensive literature search was conducted using Cumulative Index to Nursing Allied Health Literature (CINAHL) Plus with full text, Google Scholar, and evidence-based medical reviews: Cochrane DSR, ACP Journal Club, DARE, CCTR, CMR, HTA and NHSEED, Ovid SP, and PubMed. Key search terms were prediabetes, elevated glucose, diabetes, $A I C, B M I$, and prediabetes screening. Additional articles were found using the reference list from cited articles.

\section{Elevated Blood Glucose Levels}

Normal blood glucose levels increase after eating a meal but should not exceed 135-140 mg/dL (Charfen et al., 2009). A review of the literature finds a lack of consensus in what constitutes a blood glucose level indicative of "elevated blood glucose." For 
example, a random blood glucose level in a person without diabetes should be in the low to mid-100's mg/dL (Virginia Mason Team Medicine, 2013). For Ginde et al. (2009), any level less than $140 \mathrm{mg} / \mathrm{dL}$ is considered a normal glucose level. Others argue a random blood sugar, even in a healthy person without diabetes, should be less than $125 \mathrm{mg} / \mathrm{dL}$ (WebMD, 2011). The American Diabetes Association defines hyperglycemia in the hospital setting, which includes the Emergency Department, as any blood glucose $>140$ $\mathrm{mg} / \mathrm{dL}$ (ADA, 2012). Although a recent meal, stress, medications, infections, and pain may result in an elevated blood glucose level (Davidson \& Moreland, 2009), the elevated level may also be an indicator of prediabetes, which warrants further testing (Ginde et al., 2010).

An elevated blood glucose level is a warning there may be a problem, but followup tests are critical. Patients diagnosed with both impaired fasting glucose (IFG) and impaired glucose tolerance (IGT) are twice as likely to develop type 2 diabetes as those with isolated IFG or isolated IGT (Nathan et al., 2007). The term impaired fasting glucose, coined in 1997, refers to fasting plasma glucose (FPG) levels greater than 110 $125 \mathrm{mg} / \mathrm{dL}$ (Expert Committee on the Diagnosis \& Classification of Diabetes Mellitus, 1997). In 2003, the same committee lowered the FPG level to $100 \mathrm{mg} / \mathrm{dL}$ (Expert Committee on the Diagnosis \& Classification of Diabetes Mellitus, 2003). The term impaired glucose tolerance was defined by the National Diabetes Data Group as an IFG level $\geq 100$ to $<126 \mathrm{mg} / \mathrm{dl}$ and an IGT $\geq 140$ to $<200 \mathrm{mg} / \mathrm{dL}$ (1979).

In 2010, the ADA recommended another important lab test for identifying prediabetes called the glycolated hemoglobin Alc (also known as: Alc, $\mathrm{HgAlc}$ or $\mathrm{HbAlc}$ ). This blood test shows the average plasma glucose from the prior 90 days. It is a 
snapshot of what the blood glucose concentration has been over a period of time (Dugger \& Clark, 2011). An Alc of $5.7 \%$ to $6.4 \%$ is considered to be indicative of prediabetes (ADA, 2010; Buysschaert \& Bergman, 2011; Dugger \& Clark, 2011; Silverman et al., 2011).

Early identification is the first step at preventing those with prediabetes from progressing to type 2 diabetes (Gossaine \& Aldosouqi, 2010). Previous studies have indicated the ED is the ideal place to identify, inform, and refer patients for follow-up care and patients are receptive to this information and want to be notified (Ginde et al., 2007).

Ginde et al. (2009) examined if ED patients with blood glucose levels $>140$ $\mathrm{mg} / \mathrm{dL}$ were informed of their elevation and if recommendation for follow-up was provided. Twenty-one percent of the ED patients had glucose levels $>140 \mathrm{mg} / \mathrm{dL}$, yet when written discharge instructions were reviewed, less than $10 \%$ were informed about their elevated blood glucose level or were referred for follow up and further testing. A prior study by Ginde et al. (2007) showed $95 \%$ of ED patients want to be informed if they had an elevated blood glucose level.

Ginde et al. (2010) recognized the ED is an ideal place to identify patients with undiagnosed diabetes. They conducted a study of $152 \mathrm{ED}$ physicians to examine prediabetes screening of asymptomatic patients in the ED, what glucose threshold ED physicians thought warranted treatment and referral, and the barriers to referral. Findings indicated 53\% supported screening and $92 \%$ endorsed they should inform non-diabetic patients about an elevated blood glucose level. Respondents indicated a blood glucose value greater than or equal to $200 \mathrm{mg} / \mathrm{dL}$ warranted referral, but $71 \%$ believed they 
should refer for a lower blood glucose value. Approximately $25 \%$ thought they should refer as low as $160 \mathrm{mg} / \mathrm{dL}$ and $5 \%$ thought they should refer for a blood glucose level of $125 \mathrm{mg} / \mathrm{dL}$ in a non-diabetic patient.

The physicians cited several barriers to referral. Barriers for not informing and referring patients about elevated glucose levels included insufficient time and resources, outside their scope of practice, and lack of clearly defined blood glucose levels for referral and follow-up. The providers thought the Emergency Department was a good place to identify those at risk of prediabetes or those with uncontrolled diabetes, they did not feel screening those without symptoms was necessary (Ginde et al., 2010).

Combined, these studies demonstrate a knowledge gap among practitioners. Specifically, those patients who had elevated blood glucose levels and who should have been referred often were not. More basic in this process, blood glucose levels warranting referral and follow up are not clearly defined.

Risk factors for prediabetes have been identified by the Canadian Diabetes Association (2012) and the American Diabetes Association (2011): obese patients are at increased risk (Fonseca, 2007; Gossaine \& Aldosouqi, 2010; Kenealy, Elley, \& Arroll, 2007) and assessment is recommended for asymptomatic patients with a BMI greater than or equal to $25 \mathrm{~kg} / \mathrm{m} 2$, high blood pressure, and belonging to a high risk population (e.g., Aboriginal, Hispanic, Asian, South Asian, or African descent) (Canadian Diabetes Association, 2012).

\section{Risk Factors}

Demographics and other factors such as elevated BMI and high blood pressure have been found to increase the risk of having an elevated blood glucose level. An 
elevated BMI (Bergman, 2010), blood pressure, older age, and belonging to a high-risk racial or ethnic group further places the patient at risk (Charfen et al., 2009; Shaw, 2011; Shehab Eldin et al., 2008) and should be considered by the ED team when evaluating a patient. A study by James et al. (2011) found variables such as age, gender, race, and different prediabetes measures (IFG, OGT, and A1c) yield varying results. Their findings did not point to any specific test that was the defining test for the risk state of prediabetes.

Body mass index (BMI). Obesity, which is defined as a BMI greater than or equal to $30 \mathrm{~kg} / \mathrm{m} 2$, is a known risk factor for diabetes. In fact patients with BMI $>25$ $\mathrm{kg} / \mathrm{m} 2$, which is considered overweight, are also at risk. Recently a study by Chiu, Austin, Manuel, Shah, and Tu (2011) found BMI cutoffs for assessing diabetes risk vary depending on ethnicity. They looked at BMI $30 \mathrm{~kg} / \mathrm{m} 2$ as the highest risk for Caucasian participants but discovered lower BMIs put other ethnic groups at risk. The South Asian group developed diabetes with a BMI of $24 \mathrm{~kg} / \mathrm{m} 2$, the Chinese group at $25 \mathrm{~kg} / \mathrm{m} 2$, and the Black group at $26 \mathrm{~kg} / \mathrm{m} 2$. These findings support the idea people are at an increased risk of developing diabetes with a BMI as low as $24 \mathrm{~kg} / \mathrm{m} 2$.

Hoerger et al. (2007) screened 45-74 year old overweight or obese patients with a BMI greater than or equal to $25 \mathrm{~kg} / \mathrm{m} 2$ for prediabetes. They used a random capillary blood glucose test. One hundred $\mathrm{mg} / \mathrm{dL}$ was used as the indicator for having a positive test. Those screening positive received either a fasting plasma glucose test (FPG) or an oral glucose tolerance test (OGT). For those with a positive FPG or OGT, a second FPG or OGT was conducted for confirmation purposes. Next, patients with prediabetes received Diabetes Prevention Program (DPP) interventions (3 lifestyle modifications such as weight loss or 150 minutes of weekly physical activity or medication - 
metformin). An earlier study (Herman et al., 2005) found these lifestyle modifications were cost-effective and resulted in a reduction in risk for progressing to type 2 diabetes. Hoerger et al.'s (2007) findings supported those of Herman et al. (2005), arguing identification of predictors allows individuals to make lifestyle changes necessary to prevent the progression to type 2 diabetes.

Blood pressure. It is well documented a history of hypertension increases the risk of a patient having elevated blood glucose levels; thus, hypertension is a risk factor that should prompt screening for diabetes (Gossaine \& Aldosouqi, 2010). The United States Preventative Task Force also recommends screening those who are asymptomatic with hypertension, a blood pressure greater than $135 / 80 \mathrm{~mm} / \mathrm{Hg}$ (Gossaine \& Aldosouqi, 2010). Ginde et al. (2009) studied 185 patients with blood glucose levels $>140 \mathrm{mg} / \mathrm{dL}$ and of those, $54 \%$ had a history of hypertension. Elliott (2008) noted those with prediabetes should follow the same recommendation as those with diabetes, which is to maintain a blood pressure less than $130 / 80 \mathrm{mmHg}$.

Age. Ginde et al. (2009) found 64 to be the median age of those with blood glucose levels $>140 \mathrm{mg} / \mathrm{dL}$, which could be a sign of prediabetes. A study conducted by James et al. (2011) supported similar findings that age increases the prevalence of having elevated Alc levels, IGTs, and IFGs. Chiu et al. (2011) examined the incidence of diabetes in a multiethnic cohort study of 59,825 participants and found the median age for developing diabetes in South Asians was 49 years, Chinese 55 years, Blacks 57 years, and Whites 58 years. 
The ADA recommends adults aged 45 or older be tested for elevated blood glucose levels and recommends repeat blood tests every three years. Those with other risk factors should be tested earlier (ADA, 2011a). The Canadian Diabetes Association recommends everyone aged 40 or above is tested by a fasting plasma glucose test with a retest every three years (2010). This study looked at a cohort of adult patients to see what age correlates with a blood sugar level $\geq 150 \mathrm{mg} / \mathrm{dL}$.

Gender. There is a lack of clarity surrounding gender and increased risk of developing prediabetes and diabetes. Ginde et al. (2009) found no difference in risk related to gender. James et al. (2011) found no significant gender differences in elevated Alc and IGT levels; however, men were more likely than women to have elevated IFG. In contrast, Chiu et al. (2011) found men had diabetes more often than women. Their study focused on ethnic differences and found the exception was with Black patients; women were $33 \%$ more likely to have diabetes as compared to men.

Race/ethnicity. Race and ethnicity have been cited as increased risk factors for prediabetes and diabetes but studies vary in their findings about which groups are at the greatest risk. Ginde et al. (2009) found $67 \%$ of their study participants with elevated blood glucose levels greater than $140 \mathrm{mg} / \mathrm{dL}$ were White, $17 \%$ Black, $4 \%$ Hispanic, and $12 \%$ listed as "Other." Chiu et al. (2011) conducted a multiethnic cohort study of 59,824 participants (White, South Asian, Chinese, and Black). Their findings indicated the South Asian group had the highest incidence of developing diabetes, followed by the Black, White, and Chinese groups. 
The major limitation of this study was the number of participants in the nonWhite groups was significantly smaller than those in the White group. A study by James et al. (2011) found when Alc was used to test for prediabetes, non-Hispanic Blacks were almost twice as likely as non-Hispanic Whites and Mexican Americans to test positive. When IFG and IGT were used to measure risk, non-Hispanic Whites and Mexican Americans were twice as likely as Non-Hispanic Blacks to have elevated levels indicative of prediabetes. Prediabetes prevalence was similar between non-Hispanic Whites and Mexican Americans. The various findings among groups leaves a knowledge gap about which group is at the greatest risk. This study looked at race/ethnicity in the population at two EDs to see which group has the highest rate of elevated blood glucose levels $\geq 150$ $\mathrm{mg} / \mathrm{dL}$.

\section{Informing and Referring}

This study is founded on the assumption that an ED patient should be informed about an elevated random blood glucose level so he or she can follow up for further testing to determine prediabetes status. Charfen et al. (2009) conducted a study to identify patients with elevated blood glucose in the ED and refer them for follow-up testing. Their findings indicated patients with a random blood glucose level $>155 \mathrm{mg} / \mathrm{dL}$ and two risk factors end being diagnosed with diabetes or prediabetes.

Ginde, Cagliero, Nathan, and Camargo (2008) conducted a study in the Emergency Department to look for prevalence of undiagnosed diabetes and examined the correlation between random point of care (POC) glucose levels and Alc. A total of 265 participants had A1c levels tested by point of care (POC) device and lab processing. If 
the Alc level was elevated, the participants were referred for an oral glucose tolerance test. For the correlation between serum glucose level in the Emergency Department and the Alc, they controlled for age, gender, and race/ethnicity.

Findings indicated $29 \%$ of ED patients without prior diagnosis of diabetes had abnormal Alc levels and when tested further, prediabetes or diabetes was confirmed in $72 \%$ of those that had follow-up oral glucose testing. This finding was limited because only $38 \%$ of those referred went for the recommended follow up testing. Although this number is high, it does not give an accurate percentage of the population who had prediabetes $(14 \%)$. This study was, however, helpful in supporting the idea of the ED being an ideal setting to access those who may have prediabetes or diabetes. Their findings indicated blood glucose values greater than 120 to $140 \mathrm{mg} / \mathrm{dL}$. have sufficient specificity to warrant further testing. This finding supports this study and the idea that identifying those with an elevated blood glucose level and referring them for follow-up testing is vital. Failure to do this is a missed opportunity to identify potentially at-risk patients.

Once a patient is referred for follow-up and is found to have prediabetes, he or she can choose to make lifestyle choices to affect their health outcomes. This is consistent with Pender's Health Promotion Model as a framework for this study. Several landmark studies have been conducted to show the efficacy of lifestyle modifications such as diet, exercise, and even the addition of medication to prevent advancement from prediabetes to diabetes. Informing patients of their risk is key for them being able to make a decision to affect their future health. The Da Qing IGT and Diabetes Study showed those who did not make any lifestyle changes had an increased risk of developing type 2 diabetes, where 
those who had a change in diet, exercise, or both had a significant decrease in incidence of progressing to type 2 diabetes (Pan et al., 1997). This was supported in 2002, when the Diabetes Prevention Program found lifestyle modifications such as diet and exercise alone, and also with the addition of a medication called metformin, helped prevent progression from prediabetes to type 2 diabetes (Diabetes Prevention Program Research Group, 2002).

This was further supported by the Finnish Diabetes Prevention Study findings that patients can alter the course of their health with lifestyle modification (Lindstrom et al., 2003). The goal of this study is to describe the numbers of patients being seen in two EDs with elevated blood glucose levels who are not being informed. The findings will demonstrate the missed opportunity for referral, which ultimately will result in the patient not being able to make a life-altering health care decision. The intent is to heighten awareness among ED nurses and health care providers about the rate of patients potentially at risk who need to be identified and informed of their elevated blood glucose levels.

Charfen et al. (2009) conducted a two-year cohort study with 528 non-diabetic patients. Inclusion criteria were ED blood glucose levels $\geq 140 \mathrm{mg} / \mathrm{dL}$ or $\geq 126 \mathrm{mg} / \mathrm{dL}$ if more than two hours since last food intake or at least two diabetes risk factors, being a member of a high risk racial or ethnic group (African American, Hispanic, Native American, Asian American, or Pacific Islander), age 45 years or older, BMI $\geq 25 \mathrm{~kg} / \mathrm{m} 2$, or hypertension treated with medication. These risk factors are highlighted, as they are relevant to this study. Prior researchers determined those with fasting blood glucose 
levels between 100 and $149 \mathrm{mg} / \mathrm{dL}$ and $\mathrm{AlC}$ between $5 \%$ and $7.9 \%$ would be classified as prediabetic.

A blood glucose level of $\geq 150 \mathrm{mg} / \mathrm{dL}$ was selected for this study because a normal blood glucose level should be less than $125-140 \mathrm{mg} / \mathrm{dL}$, even after eating a meal (ADA, 2012; Charfen et al., 2009; WebMD, 2011). Prior studies have used the values of $>140 \mathrm{mg} / \mathrm{dL}$ as their cutoffs for those that should be referred for further testing for prediabetes (Ginde et al., 2009). The decision was also based on the prior study by Ginde et al. (2010) that found providers would refer at $200 \mathrm{mg} / \mathrm{dL}$ but thought they should refer for values greater than $160 \mathrm{mg} / \mathrm{dL}$. Some even thought they should refer for a blood glucose value greater than $125 \mathrm{mg} / \mathrm{dL}$.

The value of $\geq 150 \mathrm{mg} / \mathrm{dL}$ has not been examined in any prior studies so will be used for this one as the cutoff for examining and describing those without history of DM. This study will also look to see how elevated blood glucose levels correlate with other factors such as age, gender, ethnicity/race, BMI, and blood pressure.

\section{Summary of Literature Review}

A review of the extant literature finds (1) variation in glucose threshold levels for prediabetes; (2) various risk factors such as BMI, elevated BP, age, gender, and race/ethnicity increase the likelihood of having prediabetes; (3) provider attitudes and practices involved in informing patients about their elevated blood glucose levels and if referred for follow up (notably, education and referral for elevated blood glucose levels is not commonly implemented in the ED setting); and (4) patient attitudes and preferences to be informed and intentions to follow-up on an elevated blood glucose level. 


\section{CHAPTER III}

\section{METHODS}

The purpose of this study was to examine (1) the rates of elevated blood glucose levels $\geq 150 \mathrm{mg} / \mathrm{dL}$ in adults without a history of diabetes receiving care for a nondiabetes related emergency room visit and (2) emergency department provider patterns of informing and referring discharged ED patients without a history of DM for follow-up of elevated random blood glucose levels. In this chapter a description of the design, sample, data collection, and analytic techniques will be presented. The protection of human subjects and study limitations will also be addressed.

\section{Specific Aims}

1. To characterize a group of adults (random blood glucose, Body Mass Index [BMI], blood pressure $[\mathrm{BP}]$ ) and select demographic characteristics (age, gender, race/ethnicity) receiving care for a non-diabetes related visit to the ED.

2. To describe the relationships between and among the dependent variable of blood glucose level and independent variables (BMI, elevated BP $[\geq 130 / 80]$, history of hypertension, previous blood glucose $\geq 150 \mathrm{mg} / \mathrm{dL}$ ) and selected demographic 
characteristics in a group of adults receiving care for a non-diabetes related visit to the ED.

3. To examine the rates of elevated blood glucose $\geq 150 \mathrm{mg} / \mathrm{dL}$ in adults without a history of diabetes receiving care for a non-diabetes related emergency room visit.

4. To examine Emergency Department provider patterns of informing and referring discharged emergency department patients without a history of diabetes for follow-up of elevated random blood glucose in a group of adults receiving care for a non-diabetes related visit to the ED.

\section{Design}

A descriptive, correlational, cross-sectional design, with purposive sampling was selected for this study. Descriptive indicates the examination of variables to show what exists; the purpose of descriptive research is to accurately describe a phenomena (Key, 1997). Correlation designs are used to describe relationships among variables without seeking a cause and effect. This type of non-experimental design was appropriate for the current study because the intent was to assess whether or not a relationship exists between variables without concern for the original reason or cause of variables being studied. With this type of design, no manipulation or treatment of variables is necessary (Munro, 2005). According to Polit and Tatano Beck (2006), “Cross-sectional designs are especially appropriate for describing the status of phenomena or relationships among phenomena at a fixed point" (p. 192).

\section{Sample and Setting}

Participants were selected from all adult patients (18 years and older) seeking medical services for non-diabetes related reasons from two EDs located in North San 
Diego County $(\mathrm{N}=2,555)$, March 1, 2010 through March 22, 2010. The two hospitals are part of a community-based health care system comprised of two acute care hospitals, a long-term care facility, a skilled nursing facility, and a surgery center. One ED has approximately 30,000 patient visits per year and the other approximately 70,000 patient visits per year. A purposive sample was selected based upon the inclusion criteria: blood glucose obtained and result logged in the electronic medical record (EMR).

\section{Power Analysis}

To avoid type 2 errors, strengthen statistical conclusions, and have a large enough effect size, a power analysis was completed to estimate sample size necessary for this proposed study (Polit \& Tatano Beck, 2012). Using Green's (1991) formula $\mathrm{N}=50+8 \mathrm{~m}$ ( $m$ is the number of independent variables), $50+[8 \times 9]=50+72=122$. At minimum, 122 participants were necessary for this study, to test multiple correlations.

\section{Variables and Operational Definitions}

Table 1 lists the variables and type of variables used for this study. Operational definitions are outlined as well.

Table 1

Variables and Operational Definitions

\begin{tabular}{|l|l|}
\hline Variable/Type of Variable & Operational Definition \\
\hline Elevated blood glucose level (continuous) & Blood glucose level $\geq 150 \mathrm{mg} / \mathrm{dL}$ \\
\hline Body Mass Index (BMI) (continuous) & $\begin{array}{l}\text { BMI is the ratio of weight in kilograms to } \\
\text { the square of height in meters, calculated } \\
\text { according to the Centers for Disease Control } \\
\text { and Prevention adult charts. }\end{array}$ \\
\hline Elevated Blood Pressure (nominal/categorical) & Blood pressure $\geq 130 / 80-$ Yes or No \\
\hline
\end{tabular}




\begin{tabular}{|l|l|}
\hline $\begin{array}{l}\text { Prior blood glucose } \geq 150 \mathrm{mg} / \mathrm{dL} \\
\text { (nominal/categorical) }\end{array}$ & Yes, No, or N/A \\
\hline Age (continuous) & Age range is 18-99 years old \\
\hline Gender (nominal/categorical) & Male or female \\
\hline Race/Ethnicity (nominal/categorical) & $\begin{array}{l}\text { Caucasian, Hispanic, Asian or Pacific } \\
\text { Islander, Black, Other, Unknown }\end{array}$ \\
\hline History of Hypertension (nominal/categorical) & Yes or No \\
\hline History of Diabetes (nominal/categorical) & Yes or No \\
\hline Marital status (nominal/categorical) & $\begin{array}{l}\text { Married, Single, Divorced, Widowed, } \\
\text { Separated, Unknown }\end{array}$ \\
\hline $\begin{array}{l}\text { Reason for visit to the ED } \\
\text { (nominal/categorical) }\end{array}$ & $\begin{array}{l}\text { Abdominal, Cardiac, Neurologic, } \\
\text { Respiratory, Other }\end{array}$ \\
\hline $\begin{array}{l}\text { Discharged from the Emergency Department } \\
\text { (nominal/categorical) }\end{array}$ & Yes or No \\
\hline $\begin{array}{l}\text { Informed about elevated blood glucose level } \\
\text { (nominal/categorical) }\end{array}$ & Yes or No \\
\hline $\begin{array}{l}\text { Referred for follow up of elevated blood } \\
\text { glucose level (nominal/categorical) }\end{array}$ & Yes or No \\
\hline
\end{tabular}

\section{Data Collection}

Retrospective data were obtained from electronic medical records (EMRs) of ED patients 18 years or older seeking medical services unrelated to diabetes in two EDs in Southern California. An investigator-developed data abstraction form was used. Data were abstracted from the EMRs of patients seen on Monday, Wednesday, or Friday from March 1, 2010 through March 22, 2010, who had a blood glucose drawn and the result logged in the EMR $(\mathrm{N}=193)$.

\section{Data Analysis}

Descriptive and inferential statistics were used in this study as "an important 
aspect of statistical inference involves reporting the likely accuracy or degree of confidence, of the sample statistic that predicts the value of the population parameter" (Munro, 2005. p. 5). Descriptive statistics (means, standard deviations, percentages) were employed to illustrate the characteristics of the participants. Correlations were used to examine the relationships between blood glucose level, BMI, elevated BP $(\geq 130 / 80)$, history of hypertension, previous blood glucose $\geq 150 \mathrm{mg} / \mathrm{dL}$, reason for visit, and selected demographic characteristics (age, gender, race/ethnicity, marital status). To describe the relationships among the variables, first a correlation matrix was constructed to identify the potential for multicollinearity, which can occur when there are moderate to high correlations among predictor variables. Predictor variables scrutinized for moderate to high correlations can possibility be deleted and one variable will be reported, or variables may be combined to represent one measure of a construct to delete repetition (Mertler \& Vannatta, 2010).

In the data reported here, no multicollinearity was evidenced; therefore, relationships between the independent and dependent variables will be reported using Pearson's $r$, Phi, and Cramer's $V$. A correlation is a number that describes the degree of relationship between two variables. In probability theory and statistics correlation, it is also known as the correlation coefficient, a numeric measure of the strength of linear relationship between two random variables (Munro, 2005).

Pearson's correlation coefficient $r$ was used to calculate the relationship between age, BMI, and blood glucose level. Phi coefficient was used to calculate the correlation between blood glucose level and gender, history of hypertension, and blood pressure $\geq 130 / 80$. Cramer's $V$ coefficient was used to test the correlation between blood glucose 
level and a previous blood glucose level $\geq 150 \mathrm{mg} / \mathrm{dL}$, race/ethnicity, marital status, and reason for visit. All analyses were conducted using SPSS statistical software, version 19.

\section{Limitations}

The findings of this study must be viewed in the context of its limitations. The sample under investigation was a small although adequately powered purposive sample of a racially and ethnically diverse (although fairly homogenous with respect to regionality) group of patients receiving care in two EDs. Data were obtained through retrospective review of patient records. Using medical records as a data source introduces potential error resulting from the quality of data entry. If the patient was informed about the elevated blood glucose level and referred for follow-up but it was not documented in the discharge instructions, it was counted as a missed opportunity. Some patients who met the criteria for this study may have had diabetes, but it may not have been documented in their medical record. The blood sugar was considered random because there is no way of knowing when the patient last ate. Blood glucose could have been elevated because of the stress response, infection, or other medical reasons.

\section{Protection of Human Subjects}

Protection of human subjects included approval by the Institutional Review Committee at the health system in which the data were collected. Institutional Review Board approval was also obtained from the University of San Diego. Data were collected retrospectively. There was no patient contact; therefore, there was no risk or benefit for the participants. Precautions were taken to protect patient privacy in accordance with the Health Insurance Portability and Accountability Act (HIPAA); data were de-identified prior to transferring the information. All data were secured in a password-protected site 
on the researcher's computer. All paper records, including the codebook, are maintained in a locked drawer in the researcher's office. Data will be kept for five years then will be destroyed. 


\section{CHAPTER IV}

\section{RESULTS}

The purpose of this study was to examine (1) the rates of elevated blood glucose levels $\geq 150 \mathrm{mg} / \mathrm{dL}$ in adults without a history of diabetes receiving care for a nondiabetes related emergency room visit and (2) ED provider patterns of informing and referring discharged patients without a history of DM for follow-up of elevated random blood glucose levels. In this chapter, the results are presented. First a descriptive profile of the study participants, including their random blood glucose level, BMI, elevated BP $\geq 130 / 80$, history of hypertension, previous blood glucose $\geq 150 \mathrm{mg} / \mathrm{dL}$, and select demographic characteristics (age, gender, race/ethnicity) are presented, followed by the results related to the specific research questions.

\section{Specific Aim \#1}

To characterize a group of adults (random blood glucose, Body Mass Index [BMI], blood pressure [BP]) and select demographic characteristics (age, gender, race/ethnicity) receiving care for a non-diabetes related visit to the Emergency Department. 


\section{Sample Profile}

A total of 2,555 patients were treated in the 2 EDs over the 9-day period. Of those, 1,410 had a laboratory-based blood glucose entered and recorded in the EMR. A purposive sample $(n=193)$ included 106 patients with an elevated random blood glucose $>150 \mathrm{mg} / \mathrm{dL}$, without history of diabetes, and randomly selected patients who may have a history of diabetes $(\mathrm{n}=87)$.

Study participants ( $\mathrm{n}=193$ ) were fairly evenly distributed (Table 2 ) by gender, male $(\mathrm{n}=91)$ and female $(\mathrm{n}=102)$. Age ranged from 18 to 99 years with a mean (median 65 , sd 20.48) age of 63.8 years. Approximately half $(50.8 \%)$ were married and more than three-quarters (76.2\%) were Caucasian. Abdominal complaints were the most frequent reason for visiting the ED (32.6\%). Blood glucose levels ranged from 72 to $455 \mathrm{mg} / \mathrm{dL}$ (mean 159.69, sd 51.26; Table 3). BMI ranged from 18 to $44 \mathrm{~kg} / \mathrm{m} 2$ (mean 26.09 , sd 5.30). Twelve percent had a history of diabetes, $47 \%$ a history of hypertension, and $54 \%$ had an elevated blood pressure $(\geq 130 / 80)$ during their ED visit. Thirty-two percent had a prior blood glucose level $\geq 150 \mathrm{mg} / \mathrm{dL}$. Almost half $(47.7 \%, \mathrm{n}=92$; Table 4$)$ of the 193 patients were discharged, $46 \%(n=89)$ were admitted, and $6.2 \%(n=12)$ were transferred for admission to another hospital or a psychiatric unit. 
Table 2

Sample Characteristics

\begin{tabular}{|c|c|c|c|}
\hline & Total Sample & $\begin{array}{c}\text { BS } \geq 150 \\
\text { No History DM }\end{array}$ & $\begin{array}{c}\text { BS in EMR } \\
\text { With/Without } \\
\text { History DM }\end{array}$ \\
\hline & $(N=193)$ & $(n=106)$ & $(\mathrm{n}=87)$ \\
\hline \multicolumn{4}{|l|}{ Age } \\
\hline Mean (sd) & $63.8(20.48)$ & $66.5(20.79)$ & $60.54(19.72)$ \\
\hline Range & $18-99$ & $20-99$ & $18-95$ \\
\hline \multicolumn{4}{|l|}{$\begin{array}{l}\text { Gender } \\
\text { n (\%) }\end{array}$} \\
\hline Male & $91(47)$ & $54(51)$ & $37(42)$ \\
\hline Female & $102(53)$ & $52(49)$ & $50(58)$ \\
\hline \multicolumn{4}{|c|}{$\begin{array}{l}\text { Race/Ethnicity } \\
\text { n (\%) }\end{array}$} \\
\hline Caucasian & $147(76.2)$ & $82(77.4)$ & $65(74.7)$ \\
\hline Hispanic & $28(14.5)$ & $14(13.2)$ & $14(16.1)$ \\
\hline Asian & $6(3.1)$ & $5(4.7)$ & $1(1.15)$ \\
\hline Black & $4(2.1)$ & $2(1.9)$ & $2(2.3)$ \\
\hline Other & $5(2.6)$ & $1(0.9)$ & $4(4.6)$ \\
\hline Unknown & $3(1.6)$ & $2(1.9)$ & $1(1.15)$ \\
\hline \multicolumn{4}{|c|}{$\begin{array}{l}\text { Marital Status } \\
\text { n (\%) }\end{array}$} \\
\hline Single & $30(15.5)$ & $16(15.1)$ & $14(16)$ \\
\hline Married & $98(50.8)$ & $52(49.1)$ & $46(53)$ \\
\hline Divorced & $19(9.8)$ & $13(12.3)$ & $6(6.9)$ \\
\hline Separated & $4(2.1)$ & $2(1.9)$ & $2(2.3)$ \\
\hline Widowed & $40(20.7)$ & $21(19.8)$ & $19(21.8)$ \\
\hline Unknown & $2(1.0)$ & $2(1.9)$ & 0 \\
\hline \multicolumn{4}{|c|}{$\begin{array}{l}\text { Reason for Visit to ED } \\
\text { n (\%) }\end{array}$} \\
\hline Abdominal & $63(32.6)$ & $28(26.4)$ & $35(40.2)$ \\
\hline Chest Pain & $30(15.5)$ & $13(12.3)$ & $17(19.5)$ \\
\hline Neurologic & $40(20.7)$ & $18(17)$ & $22(25.3)$ \\
\hline Psychiatric & $12(6.2)$ & $10(9.4)$ & $2(2.3)$ \\
\hline Respiratory & $30(15.5)$ & $22(20.8)$ & $8(9.2)$ \\
\hline
\end{tabular}




\begin{tabular}{|l|l|l|l|}
\hline Other & $18(9.3)$ & $15(14.2)$ & $3(3.4)$ \\
\hline
\end{tabular}

Table 3

Health-Related Parameters

\begin{tabular}{|c|c|c|c|}
\hline & Total Sample & $\begin{array}{c}\text { BS } \geq 150 \\
\text { No History of } \\
\text { DM }\end{array}$ & $\begin{array}{c}\text { BS in EMR } \\
\text { With/Without } \\
\text { History of } \\
\text { DM }\end{array}$ \\
\hline & $(N=193)$ & $(n=106)$ & $(n=87)$ \\
\hline $\begin{array}{l}\text { Serum Blood } \\
\text { Glucose level }\end{array}$ & & & \\
\hline Mean & $159.69 \mathrm{mg} / \mathrm{dL}$ & $181.53 \mathrm{mg} / \mathrm{dL}$ & $133.09 \mathrm{mg} / \mathrm{dL}$ \\
\hline Range & $72-455 \mathrm{mg} / \mathrm{dL}$ & $150-288 \mathrm{mg} / \mathrm{dL}$ & $72-455 \mathrm{mg} / \mathrm{dL}$ \\
\hline $\begin{array}{l}\text { Blood } \\
\text { Pressure } \\
\geq 1 \mathbf{3 0} / 80\end{array}$ & & & \\
\hline n (\%) & & & \\
\hline Yes & $105(54)$ & $52(49)$ & $53(61)$ \\
\hline No & $88(46)$ & $54(51)$ & $34(39)$ \\
\hline $\begin{array}{l}\text { Previous } \\
\text { Blood Glucose } \\
\geq 150 \mathrm{mg} / \mathrm{dL} \\
\text { n (\%) }\end{array}$ & & & \\
\hline Yes & $62(32)$ & $42(40)$ & $21(24)$ \\
\hline No & $101(52)$ & $34(32)$ & $66(76)$ \\
\hline $\mathrm{N} / \mathrm{A}$ & $30(16)$ & $30(28)$ & 0 \\
\hline $\begin{array}{l}\text { History of } \\
\text { Diabetes } \\
\text { n (\%) }\end{array}$ & & & \\
\hline Yes & $24(12)$ & $0(0)$ & $23(26)$ \\
\hline No & $169(88)$ & $106(100)$ & $64(74)$ \\
\hline $\begin{array}{l}\text { History of } \\
\text { Hypertensionn } \\
(\%)\end{array}$ & & & \\
\hline Yes & $91(47)$ & $54(51)$ & $36(41)$ \\
\hline
\end{tabular}




\begin{tabular}{|c|c|c|c|}
\hline No & $102(53)$ & $52(49)$ & $51(59)$ \\
\hline BMI & & & \\
\hline Mean & $26.09 \mathrm{~kg} / \mathrm{m} 2$ & $25.83 \mathrm{~kg} / \mathrm{m} 2$ & $26.43 \mathrm{~kg} / \mathrm{m} 2$ \\
\hline Range & $18-44 \mathrm{~kg} / \mathrm{m} 2$ & $18-44 \mathrm{~kg} / \mathrm{m} 2$ & $18-37 \mathrm{~kg} / \mathrm{m} 2$ \\
\hline
\end{tabular}

Table 4

Discharge Disposition

\begin{tabular}{|l|c|c|}
\hline & $\begin{array}{c}\text { Total } \\
\text { Sample } \\
\mathbf{N}=193\end{array}$ & $\begin{array}{c}\text { Sample } \\
\mathbf{n}=106\end{array}$ \\
\hline $\begin{array}{l}\text { Admitted } \\
\mathrm{n}(\%)\end{array}$ & $89(46.1)$ & $53(50)$ \\
\hline $\begin{array}{l}\text { Discharged } \\
\mathrm{n}(\%)\end{array}$ & $92(47.7)$ & $45(42.5)$ \\
\hline $\begin{array}{l}\text { Transferred } \\
\mathrm{n}(\%)\end{array}$ & $12(6.2)$ & $8(7.5)$ \\
\hline
\end{tabular}

\section{Specific Aim $\# 2$}

To describe the relationships between and among the dependent variable of blood glucose level and independent variables (BMI, elevated BP [ $\geq 130 / 80]$, history of hypertension, previous blood glucose $\geq 150 \mathrm{mg} / \mathrm{dL}$ ) and selected demographic characteristics in a group of adults receiving care for a non-diabetes related visit to the ED.

\section{Research Question \#2}

What are the relationships between and among the dependent variable of blood glucose level and independent variables (BMI, elevated BP $[\geq 130 / 80]$, history of hypertension, previous blood glucose $\geq 150 \mathrm{mg} / \mathrm{dL}$ ) and selected demographic characteristics in a group of adults receiving care for a non-diabetes related visit to the ED? 
Inferential statistics and correlations were applied to examine the relationships between the independent variables and the dependent variable.

Table 5

Correlations Between Independent Variables and Blood Glucose Level ( $n=193)$

\begin{tabular}{|l|c|}
\hline Independent Variable & $\begin{array}{c}\text { Blood Glucose Level } \\
\boldsymbol{R}, \text { Phi }^{(\mathbf{1})} \text { or Cramer's } \boldsymbol{~}^{(2)}\end{array}$ \\
\hline BMI & $.165^{*}$ \\
\hline BP $\geq 130 / 80$ & $-.119^{1}$ \\
\hline $\begin{array}{l}\text { History of } \\
\text { Hypertension }\end{array}$ & $.120^{1}$ \\
\hline $\begin{array}{l}\text { Previous Glucose } \\
\geq 150 \text { mg/dL }\end{array}$ & $.480^{2^{* *}}$ \\
\hline Age & $.157^{*}$ \\
\hline Gender & $-.084^{1}$ \\
\hline Race/Ethnicity & $.160^{2}$ \\
\hline Reason for Visit & $.321^{2^{* *}}$ \\
\hline Marital Status & $.132^{2}$ \\
\hline
\end{tabular}

Notes: $r=$ Pearson's correlation; ${ }^{*} \mathrm{p}<.05 ;{ }^{* *} \mathrm{p}<.01$

Significant relationships were found between blood glucose level and BMI, previous blood glucose level $\geq 150 \mathrm{mg} / \mathrm{dL}$, age, and reason for visit. Increased BMI, history of a previous blood glucose level $\geq 150 \mathrm{mg} / \mathrm{dL}$, increased age, and reason for visit was significantly related to blood glucose level. 


\section{Specific Aim \#3}

To examine the rates of elevated blood glucose $\geq 150 \mathrm{mg} / \mathrm{dL}$ in adults without a history of diabetes receiving care for a non-diabetes related emergency room visit.

\section{Research Question \#3}

What are the rates of elevated blood glucose $\geq 150 \mathrm{mg} / \mathrm{dL}$ in adults without a history of diabetes receiving care for a non-diabetes related emergency room visit?

\section{Research Question \#4}

What are the characteristics of adults without a history of diabetes who presented to the ED with an elevated blood glucose level?

A total of 1,410 patients had a blood glucose level processed by the lab during this study period. Seven and a half percent $(n=106)$ met the research criteria of random blood glucose level $\geq 150 \mathrm{mg} / \mathrm{dL}$ without a history of diabetes. Age ranged from 20 to 99 years with a mean (median 69 , sd 20.8) age of 66.5 years (Table 2). Approximately half (49\%) were married, $51 \%$ were male $(n=54)$, and $77 \%$ were Caucasian. Abdominal complaints were the most frequent reason for visiting the ED (26.4\%; Table 3). Nonfasting blood glucose levels ranged from 150 to $288 \mathrm{mg} / \mathrm{dL}$ (sd 29.16) with a mean of 181.53. BMI ranged from 18 to $44 \mathrm{~kg} / \mathrm{m} 2$ (mean 25.83, sd 5.63). Fifty-one percent of patients had a history of hypertension and $49 \%$ had a blood pressure that was elevated $(\geq 130 / 80)$ during their ED visit. Forty percent had a prior blood glucose level $\geq 150$ $\mathrm{mg} / \mathrm{dL}$ documented in the medical record but were not diagnosed as having prediabetes or diabetes. Forty-five $(42.5 \%)$ of the 106 patients were discharged, $50 \%(n=53)$ were admitted, and the rest $(\mathrm{n}=\mathbf{8})$ were transferred to another hospital or a psychiatric unit for 
admission. Of those discharged $(n=45)$, only one patient $(2.2 \%)$ was informed about elevated blood glucose level and referred for follow-up.

In contrast, the additional randomly selected patients $(n=87)$ ranged in age from 18 to 95 years, with a mean (median 61, sd 19.7) age of 60.5 years (Table 2). Approximately half (53\%) were married, $42 \%$ were male ( $n=37)$, and $75 \%$ were Caucasian. Abdominal complaints were the most frequent reason for visiting the ED (40.2\%; Table 3). Nonfasting blood glucose levels ranged from 72 to $455 \mathrm{mg} / \mathrm{dL}$ (mean 133.09, sd 59.37). BMI ranged from 18 to $37 \mathrm{~kg} / \mathrm{m} 2$ (mean 26.43, sd 4.86). Forty-one percent of the patients had a history of hypertension and $61 \%$ had a blood pressure that was elevated $(\geq 130 / 80)$ during their ED visit. Twenty-four percent had a prior blood glucose level $\geq 150 \mathrm{mg} / \mathrm{dL}$ documented in the medical record but were not diagnosed as having prediabetes or diabetes.

\section{Specific Aim \#4}

To examine ED provider patterns of informing and referring discharged patients without a history of diabetes for follow-up of elevated random blood glucose, in a group of adults receiving care for a non-diabetes related visit to the ED.

\section{Research Question \#5}

What are ED provider patterns of informing and referring discharged patients without a history of diabetes for follow-up of elevated random blood glucose in a group of adults receiving care for a non-diabetes related visit to the Emergency Department?

Results showed out of 106 patients, 45 were discharged and only one (2.2\%) was informed and referred. Forty-four (97.8\%) patients were not informed or referred. 


\section{CHAPTER V}

\section{DISCUSSION OF FINDINGS}

The purpose of this study was to examine (1) the rates of elevated blood glucose levels $\geq 150 \mathrm{mg} / \mathrm{dL}$ in adults without a history of diabetes receiving care for a nondiabetes related emergency room visit and (2) emergency department provider patterns of informing and referring discharged patients without a history of DM for follow-up of elevated random blood glucose levels. In this chapter, a discussion of the findings and implications for nursing practice, education, and research are presented.

\section{Study Summary}

Retrospective data abstraction was used to obtain data for the study conducted here. A total of 2,555 patients were treated in the 2 EDs over the 9-day data collection period. Of those, 1,410 had a laboratory-based blood glucose recorded in the EMR. A purposive sample $(\mathrm{n}=193)$ included 106 patients with an elevated random blood glucose $>150 \mathrm{mg} / \mathrm{dL}$ without a history of diabetes and randomly selected patients who may have a history of DM ( $\mathrm{n}=87)$. 
Study participants ( $\mathrm{n}=193$ ) were fairly evenly distributed (Table 2 ) by gender, male $(n=91)$ and female $(n=102)$. Age ranged from 18 to 99 years with a mean (median 65 , sd 20.48) age of 63.8 years. Approximately half $(50.8 \%)$ were married and more than three-quarters (76.2\%) were Caucasian. Abdominal complaints were the most frequent reason for visiting the $\mathrm{ED}(32.6 \%)$. Blood glucose levels ranged from 72 to $455 \mathrm{mg} / \mathrm{dL}$ (mean 159.69, sd 51.26; Table 3). BMI ranged from 18 to $44 \mathrm{~kg} / \mathrm{m} 2$ (mean 26.09, sd 5.30). Twelve percent had a history of diabetes, $47 \%$ a history of hypertension, and $54 \%$ had an elevated blood pressure $(\geq 130 / 80)$ during their ED visit. Thirty-two percent had a prior blood glucose level $\geq 150 \mathrm{mg} / \mathrm{dL}$. Almost half (47.7\%, $\mathrm{n}=92$; Table 4$)$ of the 193 patients were discharged, $46 \%(n=89)$ were admitted and $6.2 \%(n=12)$ were transferred for admission to another hospital or a psychiatric unit.

Significant relationships were found between blood glucose level and BMI, previous blood glucose level $\geq 150 \mathrm{mg} / \mathrm{dL}$, age, and reason for visit. Increased BMI, history of a previous blood glucose level $\geq 150 \mathrm{mg} / \mathrm{dL}$, increased age, and reason for visit was significantly related to blood glucose level.

Approximately $7.5 \%(n=106)$ met the research criteria of random blood glucose level $\geq 150 \mathrm{mg} / \mathrm{dL}$ without a history of diabetes. Age ranged from 20 to 99 years with a mean (median 69, sd 20.8) age of 66.5 years (Table 2). Approximately half (49\%) were married, $51 \%$ were male $(\mathrm{n}=54)$, and $77 \%$ were Caucasian. Abdominal complaints were the most frequent reason for visiting the $\operatorname{ED~(26.4\% ;~Table~3).~Nonfasting~blood~glucose~}$ levels ranged from 150 to $288 \mathrm{mg} / \mathrm{dL}$ (sd 29.16) with a mean of 181.53. BMI ranged from 18 to $44 \mathrm{~kg} / \mathrm{m} 2$ (mean 25.83, sd 5.63). Fifty-one percent of the patients had a history of hypertension, and $49 \%$ had a blood pressure that was elevated $(\geq 130 / 80)$ during their 
ED visit. Forty percent had a prior blood glucose level $\geq 150 \mathrm{mg} / \mathrm{dL}$ documented in the medical record but were not diagnosed as having prediabetes or diabetes. Forty-five (42.5\%) of the 106 patients were discharged, $50 \%(n=53)$ were admitted, and the rest $(n=8)$ were transferred to another hospital or a psychiatric unit for admission. Of those discharged $(n=45)$, only one patient $(2.2 \%)$ was informed about their elevated blood glucose level and referred for follow-up.

There is a lack of agreement about what blood glucose value should be used to indicate further testing is needed to screen for prediabetes. Ginde et al. (2009) used >140 $\mathrm{mg} / \mathrm{dL}$ for their study to identify possible prediabetics. In an earlier study Ginde et al. (2008) found random blood glucose levels greater than $120-140 \mathrm{mg} / \mathrm{dL}$ were predictive of elevated $\mathrm{HbAlc}$. Further testing showed just over $1 / 3$ of those who followed up for oral glucose tolerance testing had diabetes. The inclusion criteria of a blood glucose value $\geq 150 \mathrm{mg} / \mathrm{dL}$ used in this study is even higher than the values used in prior studies; therefore, it is likely even more than $1 / 3$ of the participants in this study could have prediabetes or diabetes.

Looking at the profiles of patients with pre-diabetes, previous research has reported demographics, BMI, and history of hypertension. This is the first study to report rates of occurrence of blood pressure $\geq 130 / 80$, previous blood glucose value $\geq 150$ $\mathrm{mg} / \mathrm{dL}$, and reason for visit. The American Diabetes Association recommends diabetics maintain a blood pressure $<130 / 80$. For that reason, this value was used to examine this population of patients. For the group with blood glucose value $\geq 150 \mathrm{mg} / \mathrm{dL}$ without a history of diabetes, $49 \%$ has a blood pressure $\geq 130 / 80$. Further research is needed to see 
if that correlates with those who end up undergoing further testing and test positive for prediabetes.

No prior studies have used a previous blood glucose value $\geq 150 \mathrm{mg} / \mathrm{dL}$ to screen for prediabetes. This number was selected because multiple other glucose values above and below $150 \mathrm{mg} / \mathrm{dL}$; values as low as 125 and as high as $200 \mathrm{mg} / \mathrm{dL}$ had already been examined through research. Despite multiple studies, there is still not a guideline for ED providers to use to determine when referral is indicated. Further research is necessary to evaluate if those who present to the ED with a random blood glucose level $\geq 150 \mathrm{mg} / \mathrm{dL}$ without a history of diabetes get referred. Future research should provide demographics and risk factors on those referred if they pursue follow up testing and if they are diagnosed with prediabetes.

Significant relationships were found in this study. Blood glucose level correlated with BMI $(r=.165, \mathrm{p}<.05)$, previous blood glucose value $\geq 150 \mathrm{mg} / \mathrm{dL}$ (Cramer's $V=$ $.480, \mathrm{p}<.001)$, age $(r=.157, \mathrm{p}<.05)$, and reason for visit (Cramer's $V=.321, \mathrm{p}<.01$ ). Emergency department nurses and providers need to be aware of the significance of these relationships to help guide them as they care for patients. They show relationships between risk factors and blood glucose levels. No other studies have shown a significant correlation between history of previous blood glucose value $\geq 150 \mathrm{mg} / \mathrm{dL}$ and reason for visit.

It is not clear why this study did not show a significant correlation between blood glucose levels and elevated $\mathrm{BP} \geq 130 / 80$, history of hypertension, race/ethnicity, or gender, while previous studies cited in the literature have found they increase the risk of prediabetes and diabetes. Nonetheless, ED nurses and providers should have a heightened 
awareness of patients with an elevated blood glucose level and any of the risk factors cited in this study or in other studies cited.

Hoerger et al. (2007) completed a study to examine cost effectiveness of screening patients to identify those with prediabetes. They screened based on BMI and looked at patients age 45-74. They used these variables because these patients are more likely to have prediabetes. This is consistent with the findings of this study. This study indicated a significant relationship between blood glucose level and age $(r=.157, \mathrm{p}<$ $.05)$ and BMI $(r=.165, \mathrm{p}<.05)$.

In the study reported here, $32 \%(62 / 193)$ of the patients who had a blood glucose level documented in the EMR had an elevated random blood glucose $\geq 150 \mathrm{mg} / \mathrm{dL}$. This is important information for ED nurses and providers because it will give them an increased awareness of the prevalence. Although the exact blood glucose level that warrants follow up is not defined in the literature, this study used $\geq 150 \mathrm{mg} / \mathrm{dL}$ as the indicator for those in need of informing and referring. Follow-up testing is necessary to confirm the risk state of prediabetes or to make a diagnosis of type 2 diabetes.

Of concern, is the finding that out of 45 patients discharged from these two EDs only one (2.2\%) was informed about an elevated random blood glucose value and referred for follow up. There were 44 missed opportunities. Failing to inform and refer minimizes patients' abilities to make relevant lifestyle changes to prevent or delay progression to type 2 diabetes. This finding is significantly lower than those found by Graffeo (2001), who reported $20 \%$ of ED charts with unexplained hyperglycemia $\geq 160$ $\mathrm{mg} / \mathrm{dL}$ had documentation about referral. 
Ginde et al. (2009) used $>140 \mathrm{mg} / \mathrm{dL}$ for their inclusion criteria to assess retrospective data to evaluate if ED patients were being identified as possible prediabetics and informed about a plan for follow up. They found $10 \%$ were informed and $6 \%$ were referred. Even with a different and lower blood glucose value than that used in this study, they found a higher rate of informing and referring than was discovered in this study.

A patient may have prediabetes and its adverse micro- and macro-vascular complications for up to seven years before diabetes is diagnosed (Aroda \& Ratner, 2008; Harris, Klein, Welton, \& Knulman, 1992). Early identification and treatment of patients who may have undiagnosed prediabetes is essential in preventing or delaying progression to type 2 diabetes (Bergman, 2010; Hsueh et al., 2010).

Screening asymptomatic patients was controversial in the literature, although recommended by the ADA. This study was not done to encourage screening, but rather was founded on the idea if a provider has access to an elevated lab value, he or she should identify the abnormality, inform the patient, and refer them for follow-up. It is an opportunity not to be missed.

It is highly likely there are patients in this group of 106 who have prediabetes or diabetes. Often patients have prediabetes but are asymptomatic. With proper informing and referring, each will have the opportunity to seek follow-up and testing to confirm or reject their risk.

Many patients use the ED as a primary care setting. All ED patients are discharged with the name of a physician or clinic to follow up with; however, unless follow-up is emphasized and encouraged, many do not. If patients are asymptomatic, it is unlikely they will seek further tests or treatments. Without informing patients about an 
elevated random blood glucose level, explaining what the risks are, and referring them, they may never have another opportunity to be tested and treated.

\section{Importance to Advancement of Knowledge}

This study examined data from patients in two EDs to describe elevated random blood glucose ( $\geq 150 \mathrm{mg} / \mathrm{dL})$, BMI, elevated BP, and select demographic characteristics (age, gender, race/ethnicity) in the ED setting. It also examined the rate at which discharged ED patients were informed and referred for follow-up. This study will add to the scientific knowledge by providing data on questions not previously explored. Findings have the potential to improve ED nurses' and providers' awareness about the rates of non-diabetic patients with random blood glucose levels $\geq 150 \mathrm{mg} / \mathrm{dL}$ seen in the ED. Exploring the current practice in the ED for informing the patient about his or her elevated blood glucose level and referring him or her for follow-up serves as an indicator of missed opportunities for patients who are discharged. The study also examined the relationships between risk factors and elevated blood glucose levels in the ED population. These relationships are important to guide future intervention development and research.

\section{Conclusion and Implications for Nursing}

Pender's Health Promotion Model was the conceptual framework guiding this study. It was chosen because as the model suggests, patients will likely respond to the interpersonal influences of an ED provider informing and educating them about an elevated random blood glucose level. When the provider explains the risks involved, refers the patient for follow up and urges them to follow up for further testing, this will lead to the patient making a commitment to action. The next step is taking the action, in which the patient will follow up for further testing. If the patient does, in fact, fit the 
criteria for a prediabetes diagnosis, he or she can make important decisions about lifestyle modifications for improved health and well-being.

Indeed, research indicates the ED visit may be the only opportunity for some patients to interact with a health care provider. This makes it an ideal place to identify patients with possible prediabetes and refer them for follow-up. Emergency departments need to adopt policies to ensure providers will inform and refer patients with elevated blood glucose levels for further evaluation and treatment of the elevated blood glucose level.

ED patients are given discharge instructions upon discharge that include their diagnosis and any findings. The provider instructs them to follow-up with a specific physician or clinic. They are typically notified about abnormal findings that require follow-up. Emergency nurses must partner with other providers to educate patients with elevated random blood glucose levels about the risks and complications of prediabetes and the importance of following up on their results. ED nurses should take an active role in advocating for informing and referring by ED providers. They should also promote protocols to enable ED nurses to provide this information. Future studies are needed to identify the ongoing barriers that prevent providers from informing patients about their elevated random blood glucose levels and referring them for follow-up. 


\section{References}

Abdul-Ghani, M. A., \& DeFronzo, R. A. (2009). Pathophysiology of prediabetes. Current Diabetes Reports, 9, 193-199.

American Diabetes Association (ADA). (2010). Standards of medical care in diabetes 2010. Diabetes Care, 33(S1), 11-61.

American Diabetes Association (ADA). (2011a). Standards of medical care in diabetes II: Testing for diabetes in asymptomatic patients (Guideline Summary NGC-8217). American Diabetes Association (ADA). (2011b). Diabetes statistics: data from the 2011 National Diabetes Fact Sheet. Retrieved from http://www.diabetes.org/diabetesbasics/diabetes-statistics/

American Diabetes Association (ADA). (2012). Clinical practice recommendations. The Journal of Clinical and Applied Research and Education, 35(S1), S1-S1 10.

Aroda, V. R., \& Ratner, R. (2008). Approach to the patient with prediabetes. Journal of Clinical Endocrinology and Metabolism, 93(9), 3259-3265.

Bergman, M. (2010). Inadequacies of absolute threshold levels for diagnosing prediabetes. Diabetes Metabolism Research and Reviews, 26, 3-6.

Bergman, M. (2011). Prediabetes and diabetes prevention [Special issue]. Medical Clinic of North America, 95.

Biuso, T. J., Butterworth, S., \& Linden, A. (2007). A conceptual framework for targeting prediabetes with lifestyle, clinical, and behavioral management interventions. Disease Management, 10(1), 6-15. 
Buysschaert, M., \& Bergman, M. (2011). Definition of prediabetes. Medical Clinics of North America, 95, 289-297.

Cali, A. M. G., \& Caprio, S. (2008). Prediabetes and type 2 diabetes in youth: An emerging epidemic disease? Current Opinion in Endocrinology, Diabetes \& Obesity, 15, 123-127.

Canadian Diabetes Association. (2012). Prediabetes: A chance to change the future. Retrieved from http://www.diabetes.ca/diabetes-and-you/what/prediabetes/.

Charfen, M. A., Ipp, E., Kaji, A. H., Saleh, T., Qazi, M. F., \& Lewis, R. J. (2009). Detection of undiagnosed diabetes and prediabetic states in high-risk emergency department patients. Academic Emergency Medicine, 16(5), 394-402.

Chiu, M., Austin, P. C., Manuel, D. G., Shah, B. R., \& Tu, J. V. (2011). Deriving ethnicspecific BMI cutoff points for assessing diabetes risk. Diabetes Care, 34, 17411748 .

Colagiuri, S. (2011). Epidemiology of prediabetes. Medical Clinics of North America, 95, 299-307.

Davidson, N. K., \& Moreland, P. (2009). Stress, illness and high blood sugar [Mayo Clinic Blog]. Retrieved from http://www.mayoclinic.com/health/diabetesblog/MY00520.

Diabetes Prevention Program Research Group. (2002). Reduction in the incidence of type 2 diabetes with lifestyle intervention or metformin. New England Journal of Medicine, 346. 393-403. 
Dugger, L., \& Clark, A. P. (2011). Can hemoglobin Alc testing in hospital settings help the early identification of diabetes? Clinical Nurse Specialist: The Journal for Advanced Nursing Practice, 25, 171-175.

Elliott, W. T. (2008). Defining diagnosis and management of prediabetes. Pharmacology Watch. Retrieved from http://www.highbeam.com/doc/1G1-204625809.html.

Expert Committee on the Diagnosis \& Classification of Diabetes Mellitus. (1997). Report of the expert committee on the diagnosis and classification of diabetes. Diabetes Care, 20, 1183-1197.

Expert Committee on the Diagnosis \& Classification of Diabetes Mellitus. (2003). Report of the expert committee on the diagnosis and classification of diabetes mellitus. Diabetes Care, 26(Suppl. 1), S5-S20.

Fillman, D. S. (2010). A new focus for diabetes educators in prediabetes. The Diabetes Educator, 36(5), 684-685.

Fonseca, V. A. (2007). Identification and treatment of prediabetes to prevent progression to type 2 diabetes. Clinical Cornerstone, $8(2), 10-18$.

Ginde, A. A., Cagliero, E., Nathan, D. M., \& Camargo, C. A. (2008). Point-of-care glucose and hemoglobin Alc in emergency department patients without known diabetes: Implications for opportunistic screening. Academic Emergency Medicine, 15(12), 1241-1247.

Ginde, A. A., Delaney, K. E., Lieberman, R. M., Vanderwell, S. G., \& Camargo, C. A. (2007). Estimated risk for undiagnosed diabetes in the emergency department: A multicenter survey. Academic Emergency Medicine, 14, 492-495. 
Ginde, A. A., Delaney, K. E., Pallin, D. J., \& Camargo, C. A. (2010). Multicenter survey of emergency physician management and referral for hyperglycemia. The Journal of Emergency Medicine, 38(2), 264-267.

Ginde, A. A., Savaser, D. J., \& Camargo, C. A. (2009). Limited communication and management of emergency department hyperglycemia in hospitalized patients. Journal of Hospital Medicine, 4(1), 45-49.

Gossaine, V. V., \& Aldosouqi, S. (2010). The challenge of undiagnosed pre-diabetes, diabetes and associated cardiovascular disease. International Journal of Diabetes Mellitus, 2, 43-46.

Graffeo, C.S., \& Holland, C.K. (2001). Unexplained hyperglycemia in emergency department patients: Frequnecy, recognition, and referral practices. [Abstract]. Academic Emergency Medicine, 8, 5.

Green, S. B. (1991). How many subjects does it take to do a regression analysis? Multivariate Behavioral Research, 26, 499-510.

Harris, M. I., Klein, R., Welborn, T. A., \& Knulman, M. W. (1992). Onset of NIDDM occurs at least 4-7 years before clinical diagnosis. Diabetes Care, 15, 815-819.

Herman, W. H., Hoerger, T. J., Brandle, M., Hicks, K., Sorensen, S., Zhang, P., Hamman, R. F., ... The Diabetes Prevention Program Research Group. (2005). The cost-effectiveness of lifestyle modification or metformin in preventing type 2 diabetes in adults with impaired glucose tolerance. Annals of Internal Medicine, $142,323-332$. 
Hoerger, T. J., Hicks, K. A., Sorensen, S. W., Herman, W. H., Ratner, R. E., Ackerman, R. T., Zhang, P., ... Engelgau, M. M. (2007). Cost-effectiveness of screening for prediabetes among overweight and obese U.S. adults. Diabetes Care, 30(11), 2874-2879.

Hsueh, W. A., Orloski, L., \& Wyne, K. (2010). Prediabetes: The importance of early identification and intervention. Postgraduate Medicine, 122(4), 129-143.

James, C., Bullard, K. M., Rolka, D. B., Geiss, L. S., Williams, D. E., Cowe, C. C., Albright, A., ... Gregg, E. W. (2011). Implications of alternative definitions of prediabetes for prevalence in U.S. adults. Diabetes Care, 34, 387-391.

Kenealy, T., Elley, C. R., \& Arroll, B. (2007). Screening for diabetes and prediabetes. The Lancet, 370, 1888-1889.

Key, J. P. (1997). Research design in occupational education: Module 12, descriptive research. Oklahoma State University. Retrieved from http://www.okstate.edu/ ag/agedcm4h/academic/aged5980a/5980/newpage $110 . \mathrm{htm}$

Koh, H. K., \& Sebelius, K. G. (2010). Promoting prevention through the Affordable Care Act: Perspective. New England Journal of Medicine, 363, 1296-1299.

Lindstrom, J., Eriksson, J. G., Valle, T. T., Aunola, S., Cepaitis, Z., Hakumaki, M., Hamalainen, H., ... Salminen, V. (2003). Prevention of diabetes mellitus in subjects with impaired glucose tolerance in the Finnish Diabetes Prevention Study: Results from a randomized clinical trial. Journal of the American Society of Nephrology, 14, S108-S113.

Mertler C., \& Vannatta, R. (2010). Advanced and multivariate statistical methods: 
Practical application and interpretation (4th ed.). Glendale, CA: Pyrczak.

Munro, B.H. (2005). Statistical methods for health care research. Philadelphia: Lipincott Williams \& Wilkins.

Nathan, D. M., Davidson, M. B., DeFronzo, R. A., Heine, R. J., Henry, R. R., Pratley, R., \& Zinman, B. (2007). Impaired fasting glucose and impaired glucose tolerance. Diabetes Care, 30, 753-759.

National Diabetes Data Group. (1979). Classification and diagnosis of diabetes mellitus and other categories of glucose intolerance. Diabetes, 28, 1039-1057.

Nichols, G. A., Hiller, T. A., \& Brown, J. B. (2008). Normal fasting plasma glucose and risk of overweight and obese U.S. adults. Diabetes Care, 30(11), 2874-2879.

Norris, S.L., Kansagara, D., Bougatsos, C., \& Fu, R. (2008). Screening adults for type 2 diabetes: A review of the evidence for the U.S. preventative services task force. Annals of Internal Medicine, 148, 855-868.

Nursing Planet (2012). Health promotion model. Nursing Theories: A Companion to Nursing Theories and Models. Retrieved from http://nursingplanet.com/health_promotion_model.html

Pan, X., Li, G., Hu, Y., Wang, J., Yang, W., An, Z., Hu, Z., ... Zhang, H. (1997). Effects of diet and exercise in preventing NIDDM in people with impaired glucose tolerance: The Da Qing IGT and diabetes study. Diabetes Care, 20(4), 537-544.

Polit, D. F., \& Tatano Beck, C. (2012). Nursing research: Generating and assessing evidence for nursing practice (9th ed.). Philadelphia: Wolters Kluwer Health.

Shaw, J. (2011). Diagnosis of prediabetes. Medical Clinics of North America, 95, 341- 
352.

Shaw, J. E., Zimmet, P. Z., \& Hodge, A. M. (2000). Impaired fasting glucose: How low should it go? Diabetes Care, 23, 34-39.

Shehab Eldin, W., Emara, M., \& Soker, A. (2008). Prediabetes: A must to recognise disease state. International Journal of Clinical Practice, 62(4), 642-648.

Silverman, R. A., Pahk, R., Carbone, M., Wells, E., Mitzner, R., Burris, K., Kelson, J. R., ... Katzeff, H. (2006). The relationship of plasma glucose and hbAlc levels among emergency department patients with no prior history of diabetes mellitus. Academic Emergency Medicine, 13(7), 722-726.

Silverman, R. A., Thakker, U., Ellman, T., Wong, I., Smith, K., Ito, K., \& Graff, K. (2011). Hemoglobin Alc as a screen for previously undiagnosed prediabetes and diabetes in an acute-care setting. Diabetes Care, 34, 1908-1912.

Tuomilehto, J., Lindstrom, J., Eriksson, J. G., Valle, T. T., Hamalainen, H., IlanneParikka, P., Keinanen-Kiukaanniemi, S., ... Rastas, M. (2001). Prevention of type 2 diabetes mellitus by changes in lifestyle among subjects with impaired glucose tolerance. New England Journal of Medicine, 344(18), 1343-1350.

Vagnini, F. J. (2010). Surprising symptoms of prediabetes. The Bottom Line. Virginia Mason Medical Center. What are normal blood glucose levels? Retrieved from http:/www.bottomlinepublications.com/content/article/health-ahealing/surprising-symptoms-of-prediabetes.

Vhiu, M., Austin, P. C., Manuel, D. G., Shah, B. R., \& Tu, J. V. (2011). Deriving ethnicspecific BMI cutoff points for assessing diabetes risk. Diabetes Care, 34, 1741- 
1748.

Virginia Mason Team Medicine (2013). What are normal blood glucose levels? Virginia Mason Medical Center. Retrieved from https://www.virginiamason.org/WhatareNormalBloodGlucoseLevels

WebMD. (2011). Blood glucose. WebMD, LLC.

Retrieved from http://diabetes.webmd.com/blood-glucose

Zhang, Y., Dall, T. M., Chen, Y., Baldwain, A., Yand, W., Mann, S., Moore, V., ... Quick, W. W. (2009). Medical cost associated with prediabetes. Population Health Management, 12(3), 157-163. 
Appendices 
Appendix A

Palomar Pomerado Health

Institutional Review Committee Approval 
QUALITY MANAGEMENT

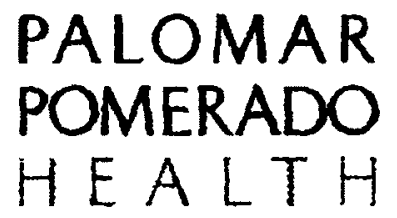

January 31,2012

Institutional Review Committee

Palomar Pomerado Health

555 E. Valley Parkway

Escondido, CA 92025

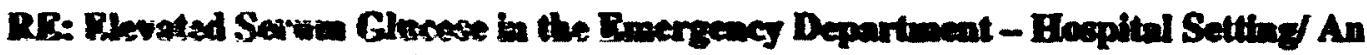

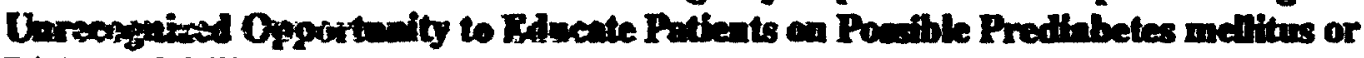
Diabetes Mellitus

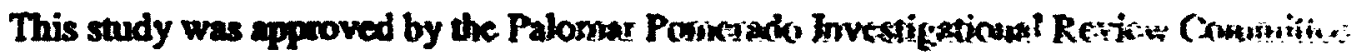

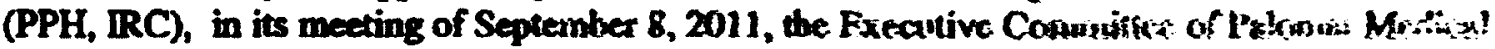

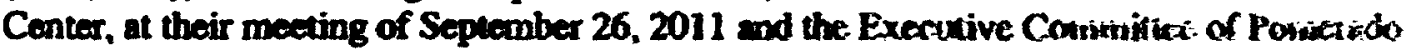
IFospital, to be conductod at Plonar Modical Ceater and Ponerado Hospital.

An amendment was submitted and approved in November 2011. Permission is requested for another amendment, to increase the number of participants to 206. Data has already been collected on 103, nondiabetic patients with blood sugar $>150 \mathrm{mg} / \mathrm{dL}$. In addition to that data, I would like to randomly select 103 patients to use as a comparison group. The electronic health record will be accessed. I would also like to collect data on all 206 patients to show if they were admitted or discharged. This will be helpful in identifying missed opportunity to educate and refer for follow up of possible prodiabetes. application.

Please accept and approve this amendment. Changes were made to pages 8 and 9 of the

Thank you in advance for your consideration.

Since-pincerely,

Melissa L. Kouse, KN, MSN, CINS-BC; CEN

PPH Clinical Nurse Specialist

Quality and Patient Safety

(760) 740-6367

Cc: Cristina Shouloy

Reviewed and approved by the Palomar Pomerado Health Investigational Review Committce.

$\overrightarrow{\text { Richard G. Just, M.D., Chairman }}$

$\frac{2-q-12}{\text { Date }}$ 